\title{
Distribution of tetraether lipids in agricultural soils - differentiation between paddy and upland management
}

\author{
Cornelia Mueller-Niggemann ${ }^{1}$, Sri Rahayu Utami ${ }^{2}$, Anika Marxen ${ }^{3}$, Kai Mangelsdorf ${ }^{4}$, Thorsten Bauersachs ${ }^{1}$, and \\ Lorenz Schwark ${ }^{1,5}$ \\ ${ }^{1}$ Institute of Geosciences, Christian Albrechts University, Kiel, Germany \\ ${ }^{2}$ Soil Science, Faculty of Agriculture, University of Brawijaya, Malang, Indonesia \\ ${ }^{3}$ Department of Soil Physics, Helmholtz Centre for Environmental Research UFZ, Halle (Saale), Germany \\ ${ }^{4}$ Helmholtz Centre Potsdam GFZ German Research Centre for Geosciences, Section 3.2 Organic Geochemistry, Potsdam, \\ Germany \\ ${ }^{5}$ WA-OIGC, Curtin University, Perth, Australia \\ Correspondence to: Cornelia Mueller-Niggemann (cmn@gpi.uni-kiel.de) and Lorenz Schwark (ls@gpi.uni-kiel.de)
}

Received: 7 September 2015 - Published in Biogeosciences Discuss.: 19 October 2015

Revised: 2 March 2016 - Accepted: 2 March 2016 - Published: 17 March 2016

\begin{abstract}
Rice paddies constitute almost a fifth of global cropland and provide more than half of the world's population with staple food. At the same time, they are a major source of methane and therewith significantly contribute to the current warming of Earth's atmosphere. Despite their apparent importance in the cycling of carbon and other elements, however, the microorganisms thriving in rice paddies are insufficiently characterized with respect to their biomolecules. Hardly any information exists on humaninduced alteration of biomolecules from natural microbial communities in paddy soils through varying management types (affecting, e.g., soil or water redox conditions, cultivated plants). Here, we determined the influence of different land use types on the distribution of glycerol dialkyl glycerol tetraethers (GDGTs), which serve as molecular indicators for microbial community structures, in rice paddy (periodically flooded) and adjacent upland (non-flooded) soils and, for further comparison, forest, bushland and marsh soils. To differentiate local effects on GDGT distribution patterns, we collected soil samples in locations from tropical (Indonesia, Vietnam and Philippines) and subtropical (China and Italy) sites. We found that differences in the distribution of isoprenoid GDGTs (iGDGTs) as well as of branched GDGTs (brGDGTs) are predominantly controlled by management type and only secondarily by climatic exposition. In general, upland soil had higher crenarchaeol contents than paddy soil, which by contrast was more enriched in GDGT-
\end{abstract}

0. The GDGT-0 / crenarchaeol ratio, indicating the enhanced presence of methanogenic archaea, was 3-27 times higher in paddy soils compared to other soils and increased with the number of rice cultivation cycles per year. The index of tetraethers consisting of 86 carbons $\left(\mathrm{TEX}_{86}\right)$ values were 1.3 times higher in upland, bushland and forest soils than in paddy soils, potentially due to differences in soil temperature. In all soils brGDGT predominated over iGDGTs with the relative abundance of brGDGTs increasing from subtropical to tropical soils. Higher branched vs. isoprenoid tetraether (BIT) values in paddy soils compared to upland soils together with higher BIT values in soils from subtropical climates indicated effects on the amounts of brGDGT induced by differences in management as well as climate. In acidic soils cyclization ratio of branched tetraethers (CBT) values correlated well with soil $\mathrm{pH}$. In neutral to alkaline soils, however, no correlation but an offset in CBT between paddy and upland managed soils was detected. This is interpreted as indicating soil moisture exerting an additional control on the CBT in these soils. Lower modified methylation index of branched tetraether $\left(\mathrm{MBT}^{\prime}\right)$ values and temperatures calculated from this $\left(T_{\mathrm{MC}}\right)$ in paddy soils compared to upland soils are attributed to a management-induced (e.g. enhanced soil moisture via flooding) effect on mean annual soil temperature (MST). 


\section{Introduction}

Isoprenoid and branched glycerol dialkyl glycerol tetraethers (GDGTs) are principal constituents of the prokaryotic cell membrane (Pearson and Ingalls, 2013; Schouten et al., 2013, and references therein). Differences in the GDGT core structures are crucial for distinguishing between the archaeal and bacterial origins of these components, with isoprenoid alkyl chains and a 2,3-di- $O$-alkyl-sn-glycerol stereoconfiguration being specific to archaea and branched alkyl chains and a 1,2di- $O$-alkyl-sn-glycerol stereoconfiguration to bacteria (Weijers et al., 2006a). Both types of tetraether lipids have a high potential to be preserved in the sediment record (Schouten et al., 2013) and have been reported in abundance from terrestrial and marine environments, e.g. in the water column and sediments of oceans and lakes (Hopmans et al., 2000, 2004; Schouten et al., 2012; Tierney and Russel, 2009; Zink et al., 2010; Naeher et al., 2014), in ponds (Tierney et al., 2012; Loomis et al., 2014; Huguet et al., 2015), in hot springs (Pearson et al., 2004; Reigstad et al., 2008; Pitcher et al., 2009), in geothermally heated soils (Peterse et al., 2009a), in peat bogs (Sinninghe Damsté et al., 2000; Weijers et al., 2006a, 2010), in grassland soils (Weijers et al., 2007, 2010; Naeher et al., 2014), in forest soils (Hopmans et al., 2004; Weijers et al., 2007, 2010), in permafrost soils (Peterse et al., 2009b; Bischoff et al., 2014), in loess soils (Huguet et al., 2012), in podzols (Huguet et al., 2010), in garden and agricultural soils (Leininger et al., 2006; Weijers et al., 2010; Sinninghe Damsté et al., 2012) as well as in paddy soils (Bannert et al., 2011; Ayari et al., 2013).

It is well known that archaea are involved in biogeochemically important processes, including methanogenesis, anaerobic methane oxidation (AMO) and aerobic ammonia oxidation (Boetius et al., 2000; Leininger et al., 2006; Thauer et al., 2008; Stahl and de la Torre, 2012; Offre et al., 2013). Distributions of isoprenoid GDGTs (iGDGTs) were initially used to characterize archaeal communities in marine environments with two major groups of archaea being distinguished: Thaumarchaeota (formerly recognized as mesophilic Crenarchaeota) and Euryarchaeota (see Pearson and Ingalls, 2013, and reference therein). Ammonia-oxidizing members of the Thaumarchaeota are currently the only known biological sources of crenarchaeol, a GDGT structure that contains four cyclopentane ring systems and an additional cyclohexane ring moiety (Sinninghe Damsté et al., 2002). In addition, Thaumarchaeota contain varying amounts of GDGTs with 0 to 4 cyclopentane rings (Sinninghe Damsté et al., 2012; Schouten et al., 2013; Pearson and Ingalls, 2013).

GDGT-0 is another common tetraether lipid that is present in a majority of archaea (Pearson and Ingalls, 2013; Schouten et al., 2013, and references therein; Villanueva et al., 2014), including for example mesophilic methanogens (Koga et al., 1998; Koga and Morii, 2005; Villanueva et al., 2014; Bauersachs et al., 2015). In addition, the presence of high abundances of GDGT- 0 at sites with active AMO suggests a close relationship between microbial consortia involved in the production and consumption of methane (Pancost et al., 2001; Blumenberg et al., 2004; Schouten et al., 2013). In periodically flooded soils (paddy soils), methanogenic lineages, such as Methanosarcinales, Methanocellales, Methanobacteriales and Methanomicrobiales, were found (Liesack et al., 2000; Watanabe et al., 2006, 2013) at varying abundances in continuously flooded as well as in alternatingly flooded and dried paddy fields (Watanabe et al., 2013). The distribution of methanogens in soils has not yet been extensively studied by using the GDGT-0 vs. crenarchaeol ratio. However, this ratio in conjunction with stable isotope analysis has been applied successfully in soils, sediments and the water column of Lake Rotsee (Naeher et al., 2014) to identify methanogenic conditions. Likewise, Ayari et al. (2013) have shown that in a rice field, where samples were collected before and after flooding, the ratio of GDGT-0 / crenarchaeol increased upon flooding, when methanogenic conditions had been established.

iGDGTs with multiple cyclopentane rings have been reported from anaerobic methanotrophic archaea (ANME) of the ANME-1 cluster as well as Thaumarchaeota and extremophilic Euryarchaeota and Crenarchaeota (Blumenberg et al., 2004; Pearson and Ingalls, 2013; Schouten et al., 2013, and references therein). The presence of iGDGTs has been predominantly investigated in marine, limnic and other aquatic habitats, but they have also been reported from soils. Here, the specific environmental conditions controlling their distribution are less well studied (Weijers et al., 2006b; Leininger et al., 2006; Sinninghe Damsté et al., 2012; Ayari et al., 2013). An improved knowledge of environmental factors influencing iGDGT compositions has been gained from cultivation experiments, which demonstrated that growth temperature, $\mathrm{pH}$ and oxygen content affect GDGT synthesis (Wuchter et al., 2004; Elling et al., 2015; Qin et al., 2015). Probably the most commonly used archaeal-based proxy in marine systems is the $\mathrm{TEX}_{86}$ (tetraether index of Thaumarchaeota-derived tetraethers consisting of 86 carbons), which correlates well with surface water temperatures (Schouten et al., 2002). Culture experiments revealed the effect of increasing temperature to raise the number of cyclopentane rings (Schouten et al., 2013, and references therein). Regional studies on altitudinal mountain transects confirmed a dependency of the iGDGT cyclization on temperatures in soil systems (Liu et al., 2013; Coffinet et al., 2014; Yang et al., 2016), but additional factors, e.g., pH or soil moisture, may influence the archaeal community and therefore the lipid composition found in soils as well (Wang et al., 2013; Xie et al., 2015).

High abundances of branched GDGT (brGDGTs) have previously been reported from soils worldwide (Weijers et al., 2007, 2010; Peterse et al., 2009a; Huguet et al., 2010, 2012). Information on the biological sources of these components, however, is still very limited (Hopmans et al., 2004; Weijers et al., 2007, 2010). Molecular investigations in peat bogs demonstrated that brGDGTs occurred in highest con- 
centrations in the catotelm, the bottom layer of peats (Weijers et al., 2006a, 2010). This was used to infer anaerobic and acid-tolerant bacterial species as brGDGT sources, e.g. microbes belonging to Acidobacteria, the most abundant bacteria in this environment (Weijers et al., 2006a, 2009, 2010). This is supported by the presence of a tetramethylated brGDGT that was recently identified in two cultured acidobacterial strains (Sinninghe Damsté et al., 2011). In addition, ether-bound 5-methyl iso-diabolic acid was detected in four mesophilic species of subdivision 4 of the Acidobacteria as a potential breakdown product of pentamethylated brGDGT (Sinninghe Damsté et al., 2014). Soil bacteria producing brGDGTs have been proposed to be obligate anaerobes following a heterotrophic mode of life (Oppermann et al., 2010; Weijers et al., 2006a, 2010). The presence of brGDGTs in oxic soils infers aerobically living bacteria to produce these lipids, but anaerobic bacteria residing in anoxic microhabitats may be possible sources as well (Schouten et al., 2013). The distribution of brGDGTs in soils is related to growth temperature (mean annual air and soil temperature) and soil pH (Schouten et al., 2002; Weijers et al., 2007, 2009; Peterse et al., 2009a, 2012). Indices which denote the degree of methylation and cyclization of brGDGTs, the methylation of branched tetraethers (MBTs) ratio and the cyclization ratio of branched tetraethers (CBT) indices, have previously been employed to reconstruct mean annual air temperatures (MATs) using a global soil calibration (Weijers et al., 2009). More recently, Peterse et al. (2012) defined the modified methylation index of branched tetraether $\left(\mathrm{MBT}^{\prime}\right)$, which represents the ratio of tetra-methylated brGDGT (GDGT-Ia, Ib and Ic) to the seven most abundant brGDGTs (GDGT-Ia, Ib, Ic, IIa, IIb, IIc and IIIa).

However, factors other than temperature and $\mathrm{pH}$ also seem to affect the distribution of brGDGTs in natural ecosystems. For example, the relatively broad scatter of calculated MAT in arid soils (Peterse et al., 2012) as well as values deviating from the trend in the highest elevations of a transect sampled on Mt. Kilimanjaro (Sinninghe Damsté et al., 2008) have been interpreted as indicating an influence of water content and vegetation type on the brGDGT pool. In addition, several authors noted that changes in the distribution of brGDGT are strongly correlated with MAT on local scales as, for example, in altitudinal transects of Mt. Rungwe and Mt. Gongga (Peterse et al., 2009c; Coffinet et al., 2014). In agricultural soils from the same area, the type of soil management and the vegetation cover can differ, leading to variable soil water contents and soil temperatures (Liu et al., 2014; Awe et al., 2015), which affect the local microbial community. Soil microbes respond to environmental stress induced by, e.g., starvation, oxygen limitation or acidification (Frostegård et al., 1993; Aanderud et al., 2015). The last of these results in the predominance of brGDGTs without cyclopentyl moieties in soils and explains the dependency of soil $\mathrm{pH}$ and CBT (Weijers et al., 2007).
Besides $\mathrm{pH}$, the redox potential (Eh) is an important factor that affects the diversity and abundance of soil microorganisms. The Eh expresses the activity of electrons which influence microbial metabolic reactions in soils. As individual microorganisms are adapted to specific Eh conditions, an increase in, e.g., soil moisture is accompanied by a decrease in Eh because of the consumption of oxygen by microbes (Husson, 2013). Further parameters, which regulate the Eh are temperature, organic matter content, or soil tillage, the last of these modifying the soil structure and soil aeration (Husson, 2013, and references therein). Agricultural management therefore may contribute to controlling redoximorphic conditions. In contrast to upland soil, i.e. without water flooding and associated crop plants, including corn or maize, wheat, barley, rape, cassava, sugar cane, cotton, banana and various vegetables, rice paddy soil management with repeated puddling of the surface soil as well as frequent flooding and alternating draining practices leads to a reduced $\mathrm{Eh}$ in the surface layer (Kögel-Knabner et al., 2010; Kölbl et al., 2014). Prevailing anoxic conditions are assumed to restrict the decomposition rate of organic matter (Lal, 2002; Sahrawat, 2005), leading to high activities of methanogenic archaea (Liesack et al., 2000) and, in combination with the application of mineral fertilizer, to high denitrification rates producing nitrous oxide (Xiong et al., 2007). In contrast, oxic conditions are associated with high Eh, as in upland soil and in paddy soil after draining where ammonia oxidation can occur. The last of these is either performed by ammonia-oxidizing archaea (AOA) or bacteria (AOB) (Leininger et al., 2006) depending on the soil $\mathrm{pH}$, with AOA being more active in acidic soils and AOB in alkaline soils (Jiang et al., 2015).

Rice serves as major staple food for $50 \%$ of the world's population and paddy rice cropland occupies an area of 157 million ha. This is equivalent to $18 \%$ of the agricultural land use area of the 10 major crops worldwide and illustrates the importance of paddy agroecosystem utilization (FAO, 2003). This profound anthropogenic influence on aquatic agroecosystems will dictate their biogeochemical and geomicrobiological properties and processes, which were determined from GDGT distribution and warrant further investigation. Only limited information on microbial assemblages and their activity in paddy soils is currently available (Bannert et al., 2011; Ayari et al., 2013). The study of such agroecosystems is of particular interest for both soil scientists and geochemists for similar reasons, as man-made environmental constraints can be compared to natural ones. To identify the anthropogenically induced ecosystem properties, reflected in microbial community structures, we studied the tetraether lipid composition in soils of different agricultural management systems, which developed in subtropical (Italy, SW China) as well as in tropical (Indonesia, Philippines, Vietnam) climates. In addition to the management type, including differences in cropping style (upland crop plants vs. wetland rice), the intensity of the management and the duration of utilization were distinctive criteria in the investi- 
gation of effects on the microbial lipids in rice paddy soil (periodically flooded), upland (non-flooded) and forest soils. This study compares non-flooded and flooded agroecosystems of different agricultural uses with respect to their GDGT composition (including GDGT palaeoproxies) to widen our knowledge on the sources and properties of GDGTs in terrestrial agroecosystems on local, regional and global scales.

\section{Material and methods}

\subsection{Sampling}

From 2008 to 2014, a total of 170 Indonesian, Vietnamese, Philippine, Chinese and Italian soils with different land use systems were collected, including 119 paddy, 37 upland, 9 forest, 2 bushland and 3 marsh samples from the topsoil horizon $(0-30 \mathrm{~cm}$ depth). The study sites are located in tropical as well as in subtropical climate zones (Fig. 1, Table 1) and agricultural soils were subject to different management techniques. Detailed soil characteristics and geographical positions of the sampling sites are given in Table S1 (Supplement). Topsoils were sampled with a soil auger as described by Klotzbücher et al. (2014).

In addition, successive land reclamation in the Chinese location Cixi via dyke construction on marine tidal flats over the last > 1000 years (Feng and Bao, 2005) led to differently aged soils, which allows us to study a 2000-year chronosequence. Based on the time of dyke construction and information from the Edit Committee of Chorography of Cixi County (1992), differently aged marsh soils (10-35 years) and agricultural soils under continuous non-irrigated upland use (50-700 years) as well as wetland rice cultivation (502000 years) were selected and sampled. The local cropping system on paddy fields is paddy-upland rotation, with one wetland rice season and one intercrop (vegetables, wheat or cereals) season per year (Cheng et al., 2009). Paddy and upland topsoils were sampled with a soil auger. Three composite samples, composed of seven subsamples each (taken in an area of $1 \mathrm{~m}^{2}$ ) and being representative of the entire field (area of $120 \mathrm{~m}^{2}$ ), were investigated at each location (for more details, see Mueller-Niggemann et al., 2012).

\subsection{Bulk geochemistry}

All soils were lyophilized, sieved to a size $<2 \mathrm{~mm}$ and ground to a fine powder using agate pestle and mortar prior to analysis. Soil $\mathrm{pH}$ was measured in a suspension of the soil in $0.01 \mathrm{M} \mathrm{CaCl}_{2}$, using a $1: 2.5(w / v)$ soil / liquid ratio. The $\mathrm{pH}$ was determined with a $\mathrm{pH}$ meter Model FG2438 (Mettler-Toledo AG, Switzerland) at ambient temperature and atmospheric pressure. The total carbon (TC) and total nitrogen (TN) contents were measured on a CNS elemental analyser Vario EL III (Elementar Analysensysteme $\mathrm{GmbH}$, Germany). The total inorganic carbon (TIC) content was determined using the Vario EL III elemental anal- yser coupled to the SoliTIC module. The soil organic carbon (SOC) was calculated as the difference between TC and TIC.

\subsection{GDGT preparation and HPLC-MS analysis}

Core lipids of iGDGTs and brGDGTs were obtained by automated solvent extraction using an ASE 200 (Dionex, USA) at a temperature of $75^{\circ} \mathrm{C}$ and a pressure $5.0 \times 10^{6} \mathrm{~Pa}$. Each sample was extracted for $20 \mathrm{~min}$ using a solvent mixture of dichloromethane (DCM) / MeOH $(93: 7, v / v)$. The total lipid extracts were separated over an aluminium oxide column into apolar and polar fractions using $n$-hexane / DCM $(9: 1, v / v)$ and DCM / MeOH $(1: 1, v / v)$ as respective eluents. The polar fractions were dried under a gentle stream of $\mathrm{N}_{2}$, redissolved in $n$-hexane / 2-propanol (99:1,v/v) and filtered through a $0.45 \mu \mathrm{m}$ polytetrafluoroethylene (PTFE) filter prior to analysis.

All samples were analysed by atmospheric pressure chemical ionization-mass spectrometry (HPLC-APCI-MS) using an Alliance 2690 HPLC (Waters, UK) and a Quattro LC triple quadrupole mass spectrometer (Micromass, UK) and following the analytical protocol described by Hopmans et al. (2000) and Schouten et al. (2007). Briefly, $10 \mu \mathrm{L}$ of the filtered polar fractions were injected into an analytical Prevail Cyano column $(2.1 \times 150 \mathrm{~mm}, 3 \mu \mathrm{m}$ particle size; Grace, USA), maintained at a temperature of $30^{\circ} \mathrm{C}$ with a constant flow rate of $0.2 \mathrm{~mL} \mathrm{~min}^{-1}$. Tetraether lipids were eluted isocratically with $99 \% n$-hexane and $1 \% 2$-propanol for $5 \mathrm{~min}$, followed by a linear gradient to $1.8 \%$ 2-propanol in $36 \mathrm{~min}$ and subsequently to $10 \%$ 2-propanol in $5 \mathrm{~min}$, after which the system was held isocratically for $5 \mathrm{~min}$. The column was re-equilibrated with $99 \% n$-hexane and 1\% 2-propanol for $12 \mathrm{~min}$ before the next injection. The MS was operated as outlined in Heyng et al. (2015), with isoprenoid and branched GDGTs being detected in the selected ion recording (SIR) mode of their protonated molecules $[\mathrm{M}+\mathrm{H}]^{+}$.

\subsection{Calculation of GDGT indices}

Abbreviations in the equations below refer to GDGTs displayed in Appendix Fig. A1. The relationship between the cyclopentane-ring-containing iGDGTs (GDGT-1 to GDGT3 vs. the crenarchaeol regioisomer) was used to calculate the TEX $_{86}$ as described by Schouten et al. (2002):

$\mathrm{TEX}_{86}=($ GDGT-2 + GDGT-3 + Cren regioisomer $) /$

(GDGT-1 + GDGT-2 + GDGT-3 + Cren regioisomer).

The CBT was calculated using the relative abundance of tetra- and penta-methylated brGDGT according to Weijers et al. (2007):

$\mathrm{CBT}=-\log ((\mathrm{Ib}+\mathrm{IIb}) /(\mathrm{Ia}+\mathrm{II} \mathrm{a}))$.

The $\mathrm{MBT}^{\prime}$ index was calculated as given in Peterse et al. (2012):

$\mathrm{MBT}^{\prime}=(\mathrm{Ia}+\mathrm{Ib}+\mathrm{Ic}) /(\mathrm{Ia}+\mathrm{Ib}+\mathrm{Ic}+\mathrm{IIa}+\mathrm{IIb}+\mathrm{IIc}+\mathrm{IIIa})$. 


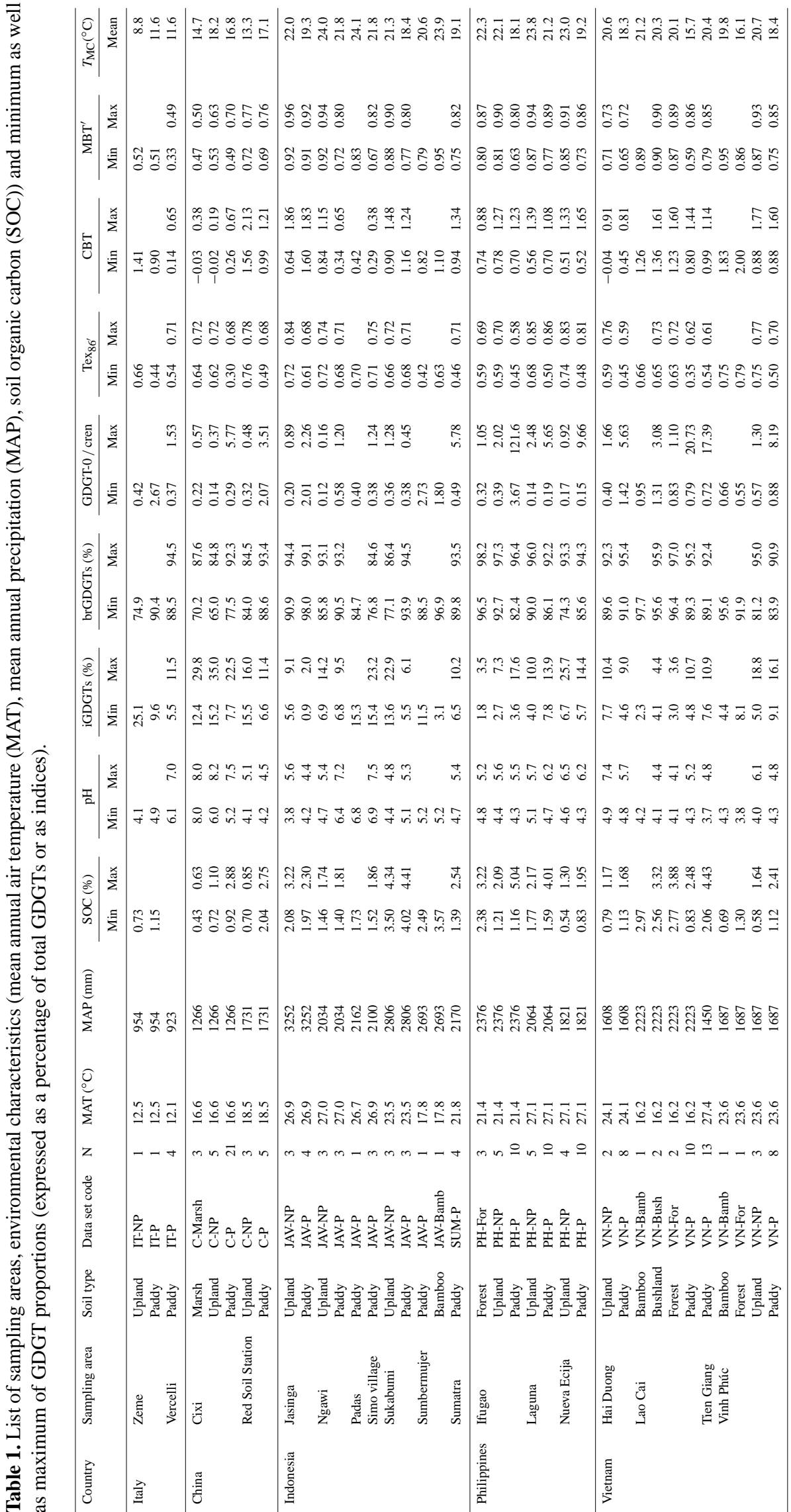





Figure 1. Map of sampling locations. Blue coloured area denotes subtropical sampling locations and green denotes tropical sampling locations.

The $\mathrm{MBT}^{\prime}$ - and CBT-derived MAT ( $\left.T_{\mathrm{MC}}\right)$ was calculated after Peterse et al. (2012):

$T_{\mathrm{MC}}=0.81-5.67 \times \mathrm{CBT}+31.0 \times \mathrm{MBT}^{\prime}$.

The branched and isoprenoid tetraether (BIT) index was determined as given in Hopmans et al. (2004):

BIT $=(\mathrm{Ia}+\mathrm{IIa}+\mathrm{IIIa}) /(\mathrm{Ia}+\mathrm{IIa}+\mathrm{IIIa}+$ Cren $)$.

\subsection{Statistical analysis}

Statistical analysis was conducted using the PASW Statistics 18 software. Principal component analysis (PCA) was performed on relative abundances of iGDGTs, brGDGTs and the different GDGT-based indices to explore and characterize the variability within the GDGT distribution in differently managed soils. To identify relationships between variables, a correlation analysis was performed. Results were given as $r$ for Pearson's correlation regression coefficient together with the $p$ value (two-tailed test), which is considered to be significant if $p$ is $<0.001$. The nonparametric Mann-Whitney $U$ test was used to investigate the significance of differences in soil properties depending on management or geographical locations. Differences are significant if $p$ is $<0.05$.

\section{Results}

SOC (Table 1) varied from 0.4 to $5.0 \%$ with highest contents present in paddy soils from the Philippine Ifugao $(5.0 \%)$ and Laguna (4.0\%), the Indonesian Sukabumi (4.4\%) and the Vietnamese Tien Giang ( $4.4 \%)$ sites. The forest and bushland soils had a mean SOC of $2.7 \pm 0.9 \%(n=11)$, which was higher than in most upland soils $(1.6 \pm 0.9 \%, n=37)$.
The $\mathrm{pH}$ ranged from 3.7 in Tien Giang (Vietnam) to 8.2 in Cixi (China; Table 1). In general, no statistically significant differences in $\mathrm{pH}$ values were noticed for soils with paddy $(5.3 \pm 1.0, n=119)$ or upland $(5.3 \pm 1.1, n=37)$ management. Forest and bushland soils had the lowest mean $\mathrm{pH}$ of $4.5 \pm 0.5(n=11)$.

Both iGDGT and brGDGT were detected in variable abundances in all soils. The brGDGT / iGDGT ratio was $>80$ in Indonesian paddy soils (Jasinga), varied between 20 and 55 in forest and bushland soils, and was between 20 and 1.9 in the remaining soils (Supplement, Fig. S1). The lowest proportion of brGDGT was noted in Italian upland soils and in very young Chinese marsh soils ( $<30$ years) and upland soils. A specific feature of soils from the Cixi area is their development on tidal wetland sediment. The GDGT signature of these soils was distinct from the one of other soils investigated in this study and represents a mixed signature of the parent substrate (tidal wetland sediments) and the recent soil organic matter (SOM).

\section{Discussion}

\subsection{Distribution of isoprenoid GDGTs in soils}

iGDGTs constitute between 0.9 and $25.7 \%$ (35\% in Cixi soils) of all GDGTs (Table 1), indicating substantial contributions of archaeal lipids to most of the investigated soils. Forest and bushland soils had lowest relative mean abundances of iGDGTs $(5.8 \pm 2.6 \%)$, followed by tropical paddy $(9.3 \pm 4.0 \%)$ and upland soils $(9.8 \pm 6.0 \%)$. The proportion of iGDGTs was highest in Chinese and Italian upland soils $(21.1 \pm 8.0 \%)$ compared to their adjacent paddy soils and 
all other remaining soils $(13.3 \pm 5.0 \%)$. The fact that the iGDGT content was significantly ( $p<0.01$; Mann-Whitney $U$ test) lower in tropical soils (including from the Philippines, Vietnam, Indonesia; $n=116$ ) compared to subtropical soils (including from China and Italy; $n=51$ ) suggests that the composition of the microbial consortia varies on regional to global scales. In addition, the differentiation between upland and paddy soils with higher amounts of iGDGTs in the former may indicate management-induced (regulating the water regime, nutrient availability, oxygen availability and/or redox conditions) variations of GDGT-containing microorganism. In general, at locations with the same climate and substrate, different management types best explain significantly different GDGT distributions ( $p<0.05$; MannWhitney $U$ test). Regardless of whether paddy, upland or forest management, all soil types differ in their microbial lipid pattern that may be influenced by differing inputs of plant organic matter, differing fertilization practices and redox conditions. The last of these is controlled by flooding and draining practices on paddy soils, which seem to favour growth and input of brGDGT-containing bacteria and/or the improved preservation of fossil brGDGTs compared to the adjacently located aerated upland soils.

iGDGT distribution patterns described from cultured archaea (Koga et al., 1998; Pancost et al., 2001; Blumenberg et al., 2004; Koga and Morii, 2005) and their comparison with soils may provide insights into the archaeal community structure and the biological processes that they mediate (Ayari et al., 2013; Yang et al., 2016). The most abundant iGDGTs in our sample set are GDGT- 0 and crenarchaeol. The latter is considered a highly specific biological marker for ammoniaoxidizing Thaumarchaeota (Leininger et al., 2006; Pitcher et al., 2010; Sinninghe Damsté et al., 2012; Pearson and Ingalls, 2013), which, in the form of groups 1.1a, 1.1b, 1.1c and 1.3, have been reported to be present in soils worldwide (Pester et al., 2012; Oton et al., 2016). Differences in the ammoniaoxidizing archaea community composition of group $1.1 \mathrm{~b}$ Thaumarchaeota in soils may be influenced by climatic conditions, as demonstrated in soils of various geographical origins (Pester et al., 2012). This dependency was not found for the relative abundance of crenarchaeol in soils investigated here using the Mann-Whitney $U$ test. To date, molecular investigations on cultivated Thaumarchaeota report GDGTs only for groups 1.1a and 1.1b (Pitcher et al., 2010, 2011; Sinninghe Damsté et al., 2012). Sinninghe Damsté et al. (2012) showed that group 1.1a Thaumarchaeota (marine and other environments) and group 1.1b Thaumarchaeota (soils and other environments) can be separated from each other based on the relative abundance of the crenarchaeol regioisomer, with a proportion of the crenarchaeol regioisomer $<5 \%$ being indicative of group 1.1a and $>10-20 \%$ of group $1.1 \mathrm{~b}$ Thaumarchaeota (Sinninghe Damsté et al., 2012). The same authors observed higher abundances of the crenarchaeol regioisomer in soils rather than in marine or lacustrine environments (Sinninghe Damsté et al., 2012). Crenarchaeol and its regioisomer are present in all analysed soil samples, which is in agreement with a previous study (Weijers et al., 2006b). The amount of crenarchaeol is generally higher in upland soils $(46.4 \pm 12.9 \%, n=37)$ compared to adjacent paddy soils ( $22.5 \pm 14.5 \%, n=119$; Fig. $2 \mathrm{a})$, possibly suggesting management-induced differences in the archaeal community structure. The abundance of the crenarchaeol regioisomer varies from 3 to $21 \%$ compared to that of crenarchaeol (mean value of $9 \pm 4 \%, n=170$ ) and shows no differences between soils and/or management types (Fig. S2).

Angel et al. (2012) observed that methanogenic archaea are ubiquitous in soils and are active only in anoxic, highly reducing environments, e.g. under flooded conditions. One distinct feature of paddy soil management vs. management of all other soils is the periodic flooding and draining of soils, which leads to highly variable redox conditions throughout the course of a year (Kögel-Knabner et al., 2010; Kölbl et al., 2014). Paddy soils are known for high methanogenic activity and as significant sources of atmospheric $\mathrm{CH}_{4}$ (Conrad, 2007; Thauer et al., 2008; Serrano-Silva et al., 2014) with little changes in the methanogenic community structure between flooding events (Krüger et al., 2005; Watanabe et al., 2006, 2009). In turn, this suggests that the overall lipid pool in paddies does not change significantly after draining the fields for harvesting.

Despite GDGT- 0 being a common component in many archaea, an elevated ratio of GDGT-0 / crenarchaeol with a threshold $>2$ has been used previously to indicate a dominance of methanogenic archaea in a given sedimentary environment. This notion primarily applied to for lake sediments, where the threshold in GDGT-0 / crenarchaeol > 2 has been attributed to methanogenesis occurring under anoxic and organic-matter-rich conditions (Blaga et al., 2009; Naeher et al., 2014). Paddy soils are known to release high amounts of methane during flooding periods (Thauer et al., 2008). Therefore, Ayari et al. (2013) suggested that the 3- to 6-fold increase in the GDGT-0 / crenarchaeol ratio, determined on the intact polar lipid fraction, in paddy soils after flooding is associated with GDGT-0 synthesis by methanogenic Euryarchaeota. We adopted this assumption and compared different kinds of soil management with respect to their iGDGT composition. In the investigated soils, the GDGT-0 / crenarchaeol ratio ranged from 0.1 to 121.6, with highest ratios observed in Philippine and Vietnamese paddy soils (Fig. 2c, Table 1). In oxic upland and forest soils the mean GDGT- 0 / crenarchaeol ratio was $\leq 1$, which indicates that methanogenic archaea are only a minor component of the microbial community at these sites. In addition, a few paddy soils (e.g. sites in Cixi and in Italy) had GDGT-0 / crenarchaeol ratios comparable to those observed in upland soils, which can be explained by the management form including higher intensities of crop rotation with upland crops under non-flooded conditions on these fields. However, if soils from the same region are compared, the ratio was generally 3-27 times higher in soils which are under paddy 



Figure 2. Box-plot diagrams of (a) crenarchaeol, (b) GDGT-0, (c) GDGT-0 / crenarchaeol ratio and (d) TEX 86 in upland (NP, brown), paddy (P, blue), marsh (grey), forest (For), bamboo cultivated (Bamb, red) and bushland (Bush, violet) soils. Abbreviations refer to different sampling locations: Italy (IT), China (C), Philippines (PH), Vietnam (VN), Sumatra (SUM) and Java (JAV). The vertical line separates subtropical from tropical locations. Numbers in all plots indicate samples listed in Table S1. The dashed line in (c) marks the GDGT$0 /$ crenarchaeol value of 2 that is the boundary to higher proportions of methanogens, which reveal values $>2$. Note the logarithmic scale for GDGT-0 / crenarchaeol ratios. Note different symbols (circle or asterisk) for outliers that are more than 1.5 (or 3) box lengths from one hinge of the box.

management compared to adjacent upland soils, indicating increased abundances and activity of methanogens in flooded soils.

$\mathrm{TEX}_{86}$ values from all sites ranged from 0.3 to 0.9 (Fig. 2d, Table 1) without an apparent geographical trend. However, $\mathrm{TEX}_{86}$ values were on average 1.3 times higher in upland, bushland and forest soils compared to the adjacent paddy soils within the same region. For example, the ratios of upland and paddy soil $\mathrm{TEX}_{86}$ values were highest in the subtropical locations of Cixi and Italy $(\sim 1.5$; Table 1). None or only minor differences in $\mathrm{TEX}_{86}$ values were noted in the Jasinga and Ngawi upland and paddy soils of Indonesia. Because of the relation between the $\mathrm{TEX}_{86}$ and temperature, one explanation for this difference could be that the periodic water layer on paddy soils may protect the soil surface from excessive heating and therefore results in lower mean annual soil temperatures (MSTs) in both soil types. Previous studies of altitudinal mountain transects support this suggestion, as the soil $\mathrm{TEX}_{86}$ was negatively correlated with elevation and therefore with decreasing temperatures, e.g. in the Qinghai-Tibetan Plateau $\left(r=-0.81, r^{2}=0.65, p<0.01\right.$; Liu et al., 2013) and Tanzania $\left(r=-0.71, r^{2}=0.50, p<0.0001\right.$; Coffinet et al., 2014).

In the soils investigated here, the relative proportion of GDGT-3 and the crenarchaeol regioisomer together with GDGT-1 mainly affected the TEX $_{86}$. Low TEX 86 values, as observed in paddy soils, are the result of high relative abundances of GDGT-1 and low proportions of GDGT-3. This suggests that paddy soil characteristics such as alternating redox conditions and higher water content control the presence of GDGT-1. High contents of cyclopentyl moieties in archaeal membrane lipids are known to be associated with ANME archaea, which synthesize significant quantities of GDGT-1, GDGT-2 and GDGT-3 (Pancost et al., 2001; Blumenberg et al., 2004). Interestingly, two divergent trends in the direction of increased $\mathrm{TEX}_{86}$ values were observed for GDGT-2 (Fig. 3a), with an increase in the GDGT-2 content to a $\mathrm{TEX}_{86}$ value of 0.70 and a subsequent decrease if values exceed this threshold (Fig. 3a). This change may again indicate that the archaeal community differs in dry upland or forest soils and flooded soils.

Fig. 3b shows that there is only a weak relationship between the relative abundance of GDGT-0 and TEX $_{86}$ 
(a)

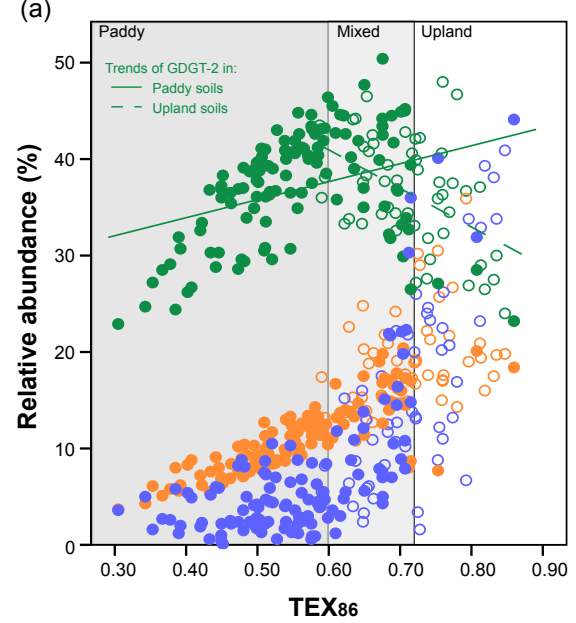

(b)

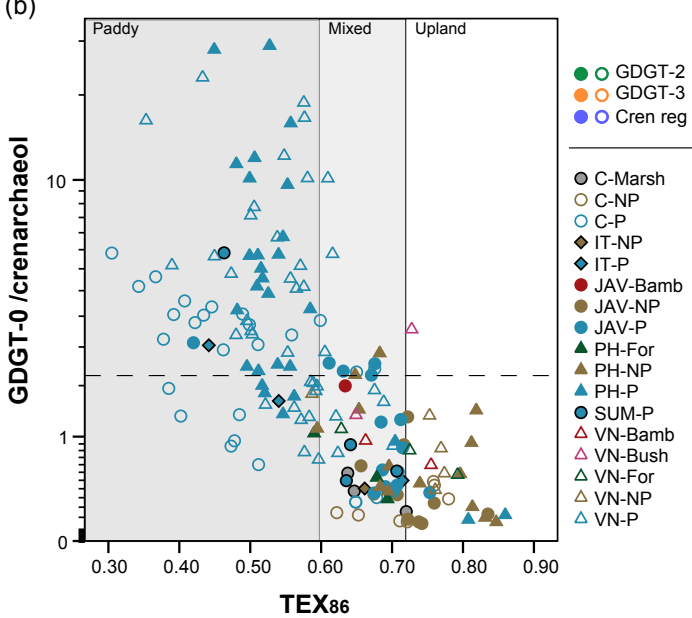

Figure 3. Cross plots showing (a) the relative abundance (\% of the sum of GDGT-1, GDGT-2, GDGT-3 and crenarchaeol regioisomer) vs. $\mathrm{TEX}_{86}$ and (b) the relationship between the most abundant iGDGTs (GDGT-0 and crenarchaeol) and lower concentrated iGDGTs (GDGT-1, GDGT-2, GDGT-3, and crenarchaeol regioisomer) as TEX 86 . GDGT-0 / crenarchaeol $>2$ and $\mathrm{TEX}_{86}<0.6$ are diagnostic for methanogens. Two outliers from the Ifugao site (Philippines) with a GDGT-0 / crenarchaeol ratio > 69 were excluded from the figure. Note the logarithmic scale for GDGT-0 / crenarchaeol ratios. The filled circles in (a) denote paddy soils and the non-filled circles denote upland, marsh, forest, bamboo and bushland soils.

(logarithmic $r=-0.67, r^{2}=0.45, p<0.0001$ ). However, both the TEX 86 and the GDGT-0 / crenarchaeol ratio show clear differences in soils under paddy (grey background in Fig. 3b) and upland management for adjacent sites, suggesting that a comparison of both parameters may allow distinguishing anoxic or oxic conditions in soils. In general, paddy soils plotted within a field characterized by GDGT-0 / crenarchaeol ratios $>2$ and TEX $_{86}$ values $<0.6$ (Fig. 3b), possibly denoting a diagnostic area for the abundance of methanogenic archaea. The GDGT-0 / crenarchaeol ratio also differs between the various paddy soils, with exceptionally high ratios in the Philippine Ifugao and Vietnamese Lao Cai soil (Table S1). At these sites, longer flooding periods (> 5 month per year) compared to Chinese and Indonesian soils are the likely explanation for the high ratios.

\subsection{Distribution of branched GDGTs in soils}

In the soils investigated here, the relative proportion of brGDGTs to the total GDGT pool was high and varied from 65.0 to $99.1 \%$ (Table 1 ). Forest soils generally contained the highest abundances of brGDGTs (>92\%), while they were significantly lower in upland and paddy soils (Fig. 4a). Pearson's correlation analysis indicated that the SOC content was not related to the relative abundance of brGDGT $(r=0.22$, $\left.r^{2}=0.05, p<0.01\right)$.

In general, the tetra-methylated GDGT-Ia was the most abundant brGDGT in acidic soil and was the only brGDGT to increase in relative abundance with decreasing $\mathrm{pH}\left(r=-0.75, r^{2}=0.56, p<0.001\right.$; Fig. 5). All other brGDGTs increased in relative abundance with $\mathrm{pH}$ $(p<0.001$; Table S2), with the highest correlations observed for GDGT Ib $\left(r=0.83, r^{2}=0.69\right)$, GDGT IIb $(r=0.79$, $\left.r^{2}=0.62\right)$ and GDGT IIIb $\left(r=0.71, r^{2}=0.50\right)$. Our results thus suggest that the monocyclization, in particular, of brGDGT is strongly controlled by $\mathrm{pH}(r=0.86$, $\left.r^{2}=0.74, p<0.001\right)$ with alkaline conditions favouring the synthesis of brGDGT with one cyclopentane moiety (Fig. 5). Similar observations have previously been made in a set of globally distributed upland soils (Weijers et al., 2007; Peterse et al., 2012).

Weijers et al. (2007) proposed the lower number of cyclopentyl moieties in brGDGT as a protection mechanism of bacterial cell membranes within acidic soils. The decrease in the amount of cyclopentyl moieties in brGDGT is thought to be associated with a decrease in membrane permeability that regulates the internal $\mathrm{pH}$ of bacteria under acidic conditions (Weijers et al., 2007). In soils investigated here, the CBT ratio varied between -0.04 to 2.13 (Table 1 ) and showed a negative correlation with increasing soil $\mathrm{pH}(r=-0.81$, $r^{2}=0.65, p<0.001$; Fig. 6a). In neutral to alkaline soils (with $\mathrm{pH}$ values > 6.5) $\mathrm{CBT}$ values stayed rather constant with an offset observed between paddy soils (mean 0.34) and upland soils (mean -0.01; Fig. 6a). Wang et al. (2014) also found no apparent correlation between $\mathrm{pH}$ and CBT in alkaline soils in a study of arid and subhumid Chinese soils. However, a predominant dependency of CBT on soil water content and the mean annual precipitation (MAP) was observed (Wang et al., 2014). In our study, varying degrees of soil moisture may be one possible explanation for the varying CBT values in paddy and upland soil, especially under alkaline conditions (Fig. 6a). 

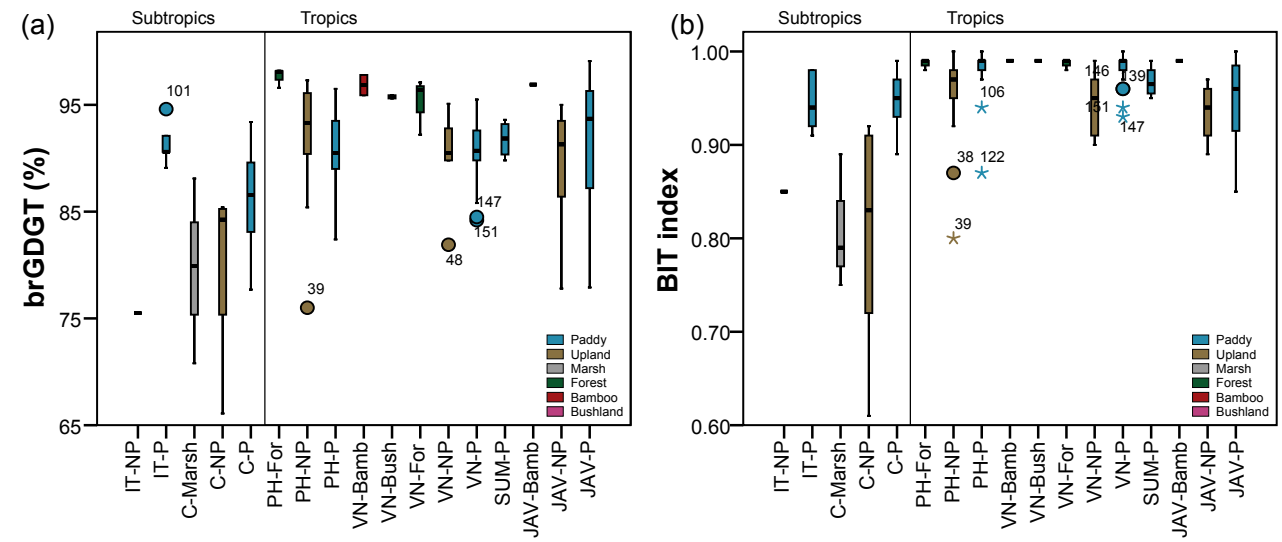

Figure 4. Box-plot diagrams of (a) the relative proportion of brGDGT in the total GDGT pool and (b) the BIT index in soil. Note different symbols (circle or asterisk) for outliers that are more than 1.5 (or 3) box lengths from one hinge of the box. Abbreviations and subdivisions as in Fig. 2.



Figure 5. Relative abundance of brGDGT plotted vs. measured soil $\mathrm{pH}$. Note logarithmic scale for relative abundance. Dashed lines indicate neutral soil conditions, which delimitate the interval between 6.6 and $7.3 \mathrm{pH}$ units.

The degree of methylation of brGDGTs $\left(\mathrm{MBT}^{\prime}\right)$ has previously been shown to correlate with MAT and $\mathrm{pH}$ (Weijers et al., 2007; Peterse et al., 2012). Our results demonstrate that the $\mathrm{MBT}^{\prime}$ generally shows low values in paddy soils compared to the adjacently located upland soils, except for the Chinese soils of Cixi (Table 1). The difference in $\mathrm{MBT}^{\prime}$ between soils from the same sampling area denotes a lower influence of MAT on the $\mathrm{MBT}^{\prime}$ than on the $\mathrm{pH}$, which was weakly related to the $\mathrm{MBT}^{\prime}(r=-0.55$, $r^{2}=0.31, p<0.001$; Fig. 6 b). The $\mathrm{MBT}^{\prime}$ was mainly controlled by the relative abundance of GDGT-Ia and GDGTIIa, both of which were strongly related to MAP (Peterse et al., 2012). As the latter is largely similar at adjacent sites, we consider the paddy-soil-specific management techniques, including periodically flooding the soils, as responsible for the low GDGT-Ia and high GDGT-IIa content in paddy soils compared to upland soils (Table S1).The temperatures inferred from brGDGT patterns, i.e. $T_{\mathrm{MC}}$ values, were generally lower in paddy soils compared to the adjacent upland soils (Table 1), suggesting that $T_{\mathrm{MC}}$ reflects mean annual soil temperature rather than air temperature. Vegetation cover and soil moisture affect soil temperature, in particular in surface soils (Seneviratne et al., 2010; Liu et al., 2014; Awe et al., 2015). This led us to hypothesize that soil moisture and/or soil temperature regulates composition of brGDGTs in adjacent subaquatic and upland soils of identical air temperature as recognized by their respective $T_{\mathrm{MC}}$.

A recently developed method separates the structural isomers of brGDGTs from their methyl groups located at positions 5 and 6 (De Jonge et al., 2013). De Jonge et al. (2014) showed that the new $\mathrm{CBT}_{5 \mathrm{ME}}$, calculated without 6-methyl brGDGTs, correlated more strongly with soil $\mathrm{pH}$ than the regular CBT, which includes both isomers, the 5- and 6methyl brGDGTs. In addition, these authors found no correlation between $\mathrm{pH}$ and the newly developed $\mathrm{MBT}_{5 \mathrm{ME}}^{\prime}$, which is calculated without the 6-methyl isomer, but a stronger correlation of this index with MAT. De Jonge et al. (2014) thus demonstrated that co-elution of GDGTs can affect estimation of $\mathrm{pH}$ values. Conventional methods, such as the one employed in this study, are not suited to fully separate the different structural isomers of brGDGTs, and hence it is possible that some scatter observed between our CBTreconstructed and measured $\mathrm{pH}$ may result from the analytical set-up (Fig. 6a). However, the overall good covariation of $\mathrm{CBT}$ and $\mathrm{pH}$ for our sites suggests that the partial co-elution of brGDGT only had a minor effect on the calculation of the lipid-based proxies used in this study. 
(a)

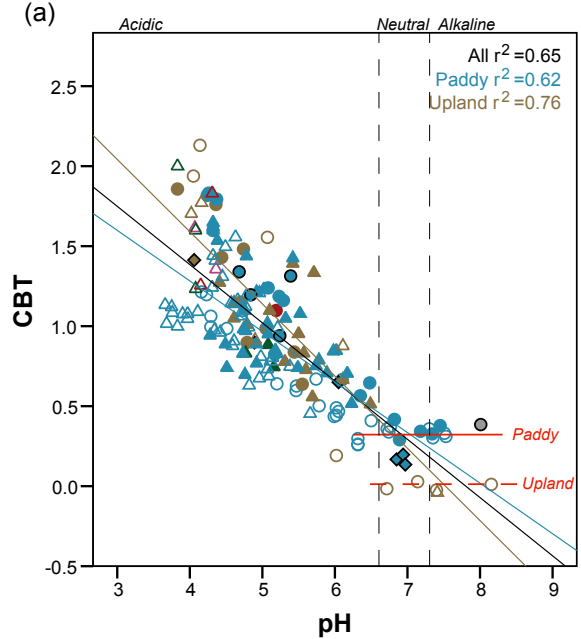

(b)



Figure 6. Plot of (a) the cyclization ratio of branched tetraethers (CBT) vs. soil pH and of (b) the modified methylation index of branched tetraethers $\left(\mathrm{MBT}^{\prime}\right)$ vs. soil $\mathrm{pH}$. Dashed lines indicate neutral soil conditions, which delimitate the interval between 6.6 and $7.3 \mathrm{pH}$ units. Regressions line of all soils is black, the line of upland, marsh, forest, bamboo and bushland soils is brown and the line for paddy soils is blue. Abbreviations as in Fig. 2. Red lines in (a) show the offset between paddy and upland soil, which have $>6.2 \mathrm{pH}$ values.

\subsection{Influence of management systems on GDGT distributions}

The BIT index quantifies the relationship between acyclic brGDGTs and crenarchaeol and has been used previously to determine the input of terrestrially derived organic matter to marine and lake environments (Hopmans et al., 2004; Weijers et al., 2007). The interpretation of BIT values in soil is not that straight forward as all GDGTs are terrestrially derived. Thus, variations in BIT values must be governed by a microbial input whose GDGT distribution is currently only incompletely known. Wang et al. (2013) observed a positive correlation between increasing soil water content and BIT values in Chinese marsh soils. In our sample set, the BIT index was slightly higher in paddy soils than in the adjacent upland soils (Fig. 4b). Furthermore, higher values were observed generally in paddy soils from tropic (1.02-1.04-fold) compared to subtropic (1.07-1.11-fold) locations. In contrast to the general trend, we found highest BIT values (1.27fold) in the subtropical paddy soils of the Cixi location. In this area, the BIT values in marsh and upland soils (0.610.89 ) were comparatively low, indicating that the latter have a mixed lipid composition, with crenarchaeol originating predominantly from the residual parent substrate (tidal wetland sediment) and in smaller quantities also from the current microbial soil community. Similar results were found in a study of plant wax lipids, which confirm the mixed organic matter composition in these soils (Mueller-Niggemann and Schwark, 2015). Except for the higher contribution of crenarchaeol to the marsh soils, our results show that brGDGTs clearly dominate over iGDGTs originating from Thaumarchaeota in all of the investigated soil types. Interestingly, based on relations of brGDGTs to crenarchaeol, Thaumar- chaeota seem to be more abundant in upland soils compared to forest and periodically flooded paddy soils (Fig. 4b). Low redox conditions as assumed for paddy soils may thus lead to an enrichment of brGDGTs either by higher production or increased preservation of brGDGTs compared to crenarchaeol in wetland soils. Our results thus contradict those of Peterse et al. (2015), who performed a 152-day experimental study, where soils were incubated under water to simulate the development of an aquatic environment under aerobic conditions. Contrastingly to our observations, lower BIT values were measured in flooded soils, potentially due to a higher contribution of crenarchaeol while brGDGTs remained unchanged until the end of the experiment.

PCA was performed to obtain information on the major factors that control the variability of the distribution of iGDGTs and brGDGTs. Results of this analysis indicate that crenarchaeol exerts a major control on the iGDGT composition in upland soils (Fig. 7a). The component loading score of GDGT-0 is opposite to crenarchaeol and has the highest negative score in PC1. In general, soils can be sorted into two groups on the basis of their scores on the first component. Paddy soils load negatively and all other soils load positively on PC1. Paddy soils that plot in the quadrant of upland soils are characterized by a higher intensity of crop rotation with upland crops on the fields. The iGDGT composition of periodically flooded paddy soils is mainly controlled by GDGT-0 and that of non-paddy upland soils by crenarchaeol derived from Thaumarchaeota. In flooded rice paddy soils, oxygen availability determines the development of microbial consortia adapted to more anoxic conditions such as GDGT-0synthesizing methanogenic archaea (Koga et al., 1998; Koga and Morii, 2005). The variance in PC2 is mainly associated 
(a)



(b)



Figure 7. Principal component analysis (PCA) based on standardized relative abundances of six iGDGTs in 170 investigated soils. The first principal component (PC1) accounted for $53.9 \%$ of the total variance and the second (PC2) for 29.9\%. Panel (a): symbols and colours in upper legend denote different management forms. Abbreviations as in Fig. 2. Panel (b): colours of the sample site symbols in lower legend are indicative of the number of rice cultivation cycles per year ("No. of rice $\mathrm{yr}^{-1}$ ").

with the relative abundance of GDGT-2 and separating forest and bushland soils from all other soils. The larger scatter of paddy soils on PC2 is explained by the number of rice cultivation cycles per year, which apparently influence the GDGT-2 content significantly (Fig. 7b). Methanogenic archaea were found to be phylogenetically related to ANME archaea (Krüger et al., 2003; Shima et al., 2012). ANME archaea are a well-known source of iGDGTs (including GDGT-2) in natural environments (Pancost et al., 2001; Blumenberg et al., 2004). Both the interaction of methanogenic and methanotrophic archaea as well as the fact that ANME are an abundant source of GDGT- 2 could explain the relationship between higher numbers of rice cultivation cycles, which induce increased methanogenesis through abundant redox cycling, and the presence of GDGT-2. MAT and MAP had no obvious influence on discriminating between different types of agricultural soil via iGDGT distribution (Fig. S3).

PCA analysis of the relative abundances of brGDGT shows an opposite relation of GDGT-Ia to all other brGDGTs, with the highest component loading score on PC1 for GDGT-Ia (Fig. 8). The cyclopentane-ring-containing GDGT-IIb and GDGT-IIIb plot negatively on PC1. Higher contents of GDGT-Ia in upland soils compared to adjacent paddy soils (Table S1) confirm that tetra-methylated brGDGTs may be useful in separating different agricultural soils. GDGT-IIa has the lowest loading score on PC1 but the highest on PC2. Upland soils load separately from paddy soils along the $\mathrm{PC} 2$, with a variation of relative abundance of the cyclic GDGT-Ib and GDGT-Ic playing the most important role. In contrast, paddy soils are mainly influenced by the abundance of GDGT-IIa and GDGT-IIIa, which both show only a low correlation with $\mathrm{pH}$ (Table $\mathrm{S} 2$ ). We rather assume that they are dependent on soil moisture, due to the lack of correlation between the GDGT distribution and soil properties (e.g. pH) as well as climate factors (e.g. precipitation, air temperature) in adjacently located paddy and upland soils. The main ecological difference between paddy and upland soil is the water budget, and thus we interpret this environmental variable as causing the offset in GDGTs. The first PC, explaining $69.11 \%$ of the variance, indicates a separation between locations, with a strong negative score in subtropical Italian and Chinese soils and more positive scores in soils originating from the tropics (Fig. 8a). The MAP (Fig. 8b) and MAT (Fig. S4) gradients of sampling locations on PC1 confirm a relation of climatic parameters to the variation of acyclic brGDGTs.

PCA analysis of environmental parameters as well as of indices of bacterial and archaeal GDGTs indicated that separation of paddy and upland soil is mainly controlled by the intensity of methanogenesis (Fig. 9a). The GDGT$0 /$ crenarchaeol ratio and the BIT index had the highest positive loading score on PC2. The SOC and TN loaded in the same quadrant as the BIT index, suggesting that a positive correlation between the amount of organic matter and acyclic brGDGT, especially in paddy soils, prevailed. Alternating anoxic conditions in paddy soils are known to favour the preservation and therefore the accumulation of organic matter (Lal et al., 2002), which could lead to an increase in heterotrophic and brGDGT-producing bacteria. In general, the CBT loading was the opposite of that of the soil $\mathrm{pH}$ on $\mathrm{PC} 1$, indicating their negative relation to each other. The internal separation of paddy soils via the number of rice cultivation cycles is evident by high loading scores of the CBT and $\mathrm{MBT}^{\prime}$ (Fig. 9b). Apparently, the increase in the MBT' is linked to the number of rice cycles and therefore to the lowering of penta- and hexa-methylated brGDGT during in- 
(a)

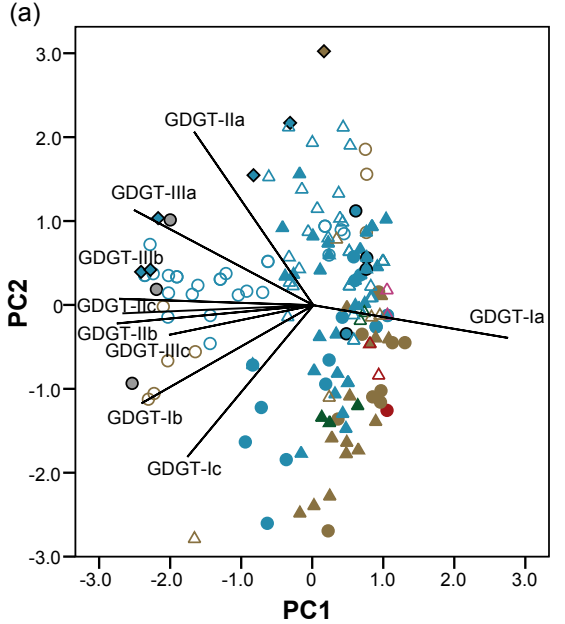

(b)

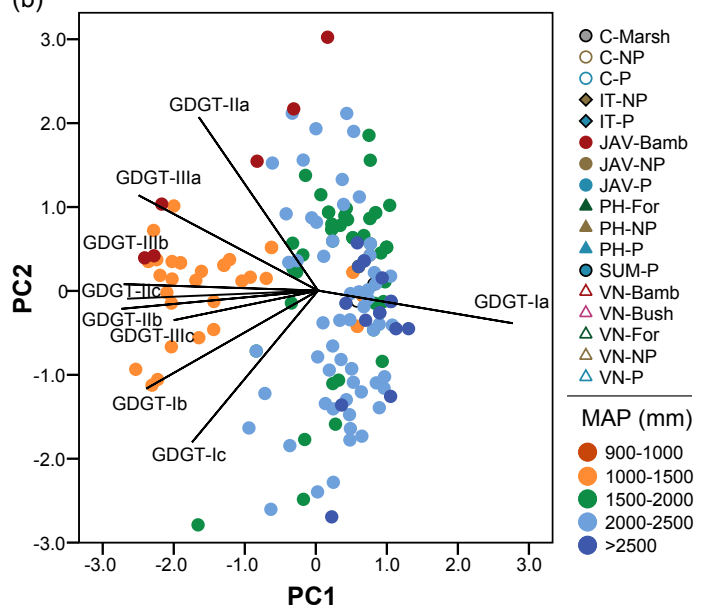

Figure 8. Principal component analysis (PCA) based on standardized relative abundances of nine brGDGTs in 170 investigated soils. The first principal component (PC1) accounts for $69.1 \%$ of the variance and the second (PC2) for 14.3\%. Panel (a): symbols and colours in upper legend denote different management forms. Abbreviations as in Fig. 2. Panel (b): colours of the sample site symbols in lower legend are indicative of the mean annual precipitation.
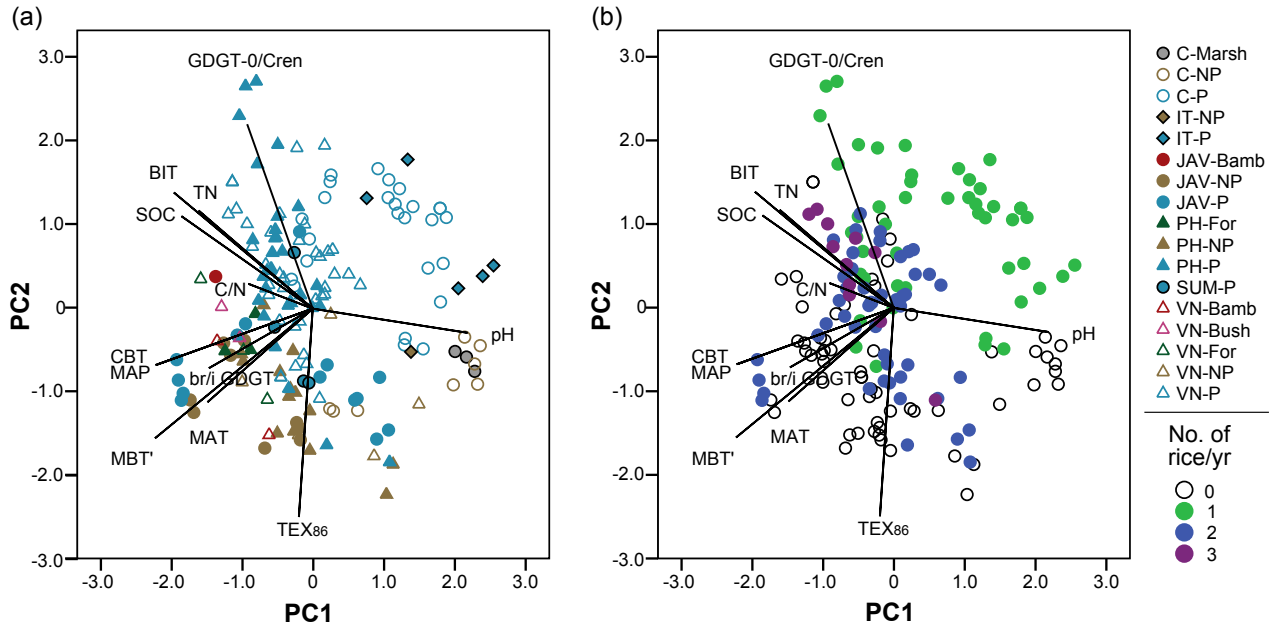

Figure 9. Principal component analysis (PCA) based on commonly used indices and ratios for the 170 investigated soils. The first principal component (PC1) accounts for $33.5 \%$ of the variance and the second (PC2) for $21.4 \%$. Panel (a): symbols and colours in upper legend denote different management forms. Abbreviations as in Fig. 2. Panel (b): colours of the sample site symbols in lower legend are indicative of the number of rice cultivation cycles per year ("No. of rice $\mathrm{yr}^{-1}$ ").

creasing redox cycles. Similar loading scores as well as similar directions of climatic parameters, such as MAP and MAT, and of $\mathrm{CBT}$ and $\mathrm{MBT}^{\prime}$ also indicated that these factors were linked to each other. In addition to methanogenesis, differences in MAT and soil water content seemed to be secondary factors controlling the distribution of brGDGT in soils, which also allowed a separation between upland and paddy management. It should be considered though that MAT is not identical to MST as the latter was also affected by, e.g., the albedo and soil management, which can be different in the adjacent soils (Liu et al., 2014; Awe et al., 2015, and references therein). The reflection coefficient of the surface differs in agricultural soils as a consequence of management practices, which influence the soil bulk density (via tillage), the plant cover (function of the crop leaf area index) and the soil water content. For example, Awe et al. (2015) found differences in soil temperature as a consequence of management practices, with lower temperatures in soils under chiselling and conventional tillage compared to no tillage. 

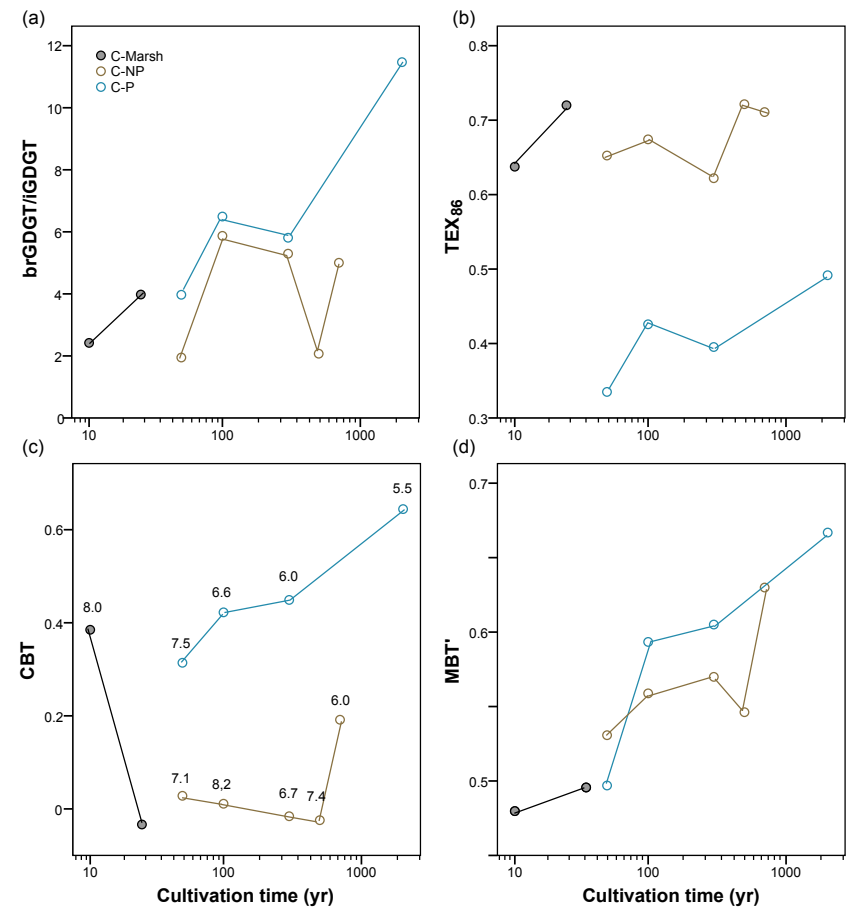

Figure 10. Time plots of various GDGT ratios and indices in soils of the Chinese Cixi region: (a) ratio of branched vs. isoprenoid GDGTs, (b) the $\mathrm{TEX}_{86}$, (c) the CBT and (d) $\mathrm{MBT}^{\prime}$. Note logarithmic scale for the cultivation time. Numbers in plot (c) reflect soil $\mathrm{pH}$ values.

\subsection{Effects of long-term management on GDGT distributions}

Changes in GDGT distribution within two Cixi chronosequences with different cropping systems, one under continuous non-flooded upland and the other under paddy management, indicated specific adaption processes during the long-term usage at each site. Marsh soils were the first soils to develop after the construction of dykes on tidal wetland sediments and therefore represent the starting point of the subsequent soil development. We observed high BIT values $(\sim 0.77)$ already in the surface horizon of the marsh soils, indicating the rapid adaption of the microbial community to more terrestrial conditions. A plot of the brGDGT / iGDGT ratio over time provides evidence for a dominance of brGDGT over iGDGT in all soils, with values of this ratio varying between 2 and 6 in upland soils (Fig. 10a). In contrast to paddy soils, which had a 4-fold increase in the ratio after 2000 years of rice cultivation, such an increase suggests an influence of long-term processes on the proportion of archaeal and bacterial soil microorganisms. These processes may include desalinization, decalcification through leaching as shown in changes in soil $\mathrm{pH}$ values (Fig. S5a), fertilization activities, and organic matter input and accumulation (Fig. S5b). Paddy soil manage-

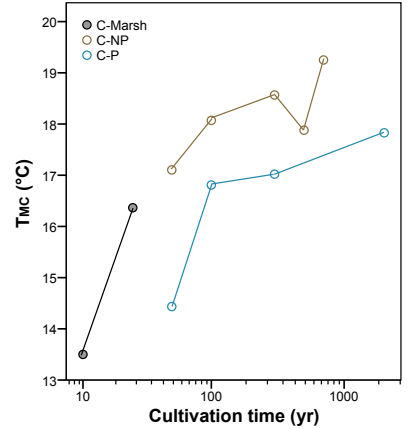

Figure 11. Time plot of $\mathrm{MBT}^{\prime}-\mathrm{CBT}$-derived temperatures $\left(T_{\mathrm{MC}}\right)$ in soils of Cixi. Note logarithmic scale for cultivation time.

ment is known to strongly affect the accumulation of organic matter (Wu, 2011; Mueller-Niggemann et al., 2012; Kölbl et al., 2014) as the periodically anaerobic conditions result in a slower degradation of organic matter (Lal et al., 2002). Kölbl et al. (2014) investigated the response of redox dynamics to changing water conditions over a 1-year time period in 100, 700- and 2000-year-old paddy soils. They noted a change in the redox potential towards anoxic conditions, already after 5 days of flooding. After stabilization, the redox potential was in the same range in all soils $(-170$ to $-200 \mathrm{mV})$, independent of the duration of paddy management. In upland soils, permanent oxic conditions were persistent throughout the time period investigated. The results of Kölbl et al. (2014) demonstrate that the rapid establishment of anoxic conditions and the long-term usage of paddy soils may lead to an increase in organic carbon concentrations over time.

Within the upland soil chronosequence, the $\mathrm{TEX}_{86}$ does not change significantly over the 700 -year cultivation time and averages 0.7 (Fig. 10b). In paddy soils, by contrast, the $\mathrm{TEX}_{86}$ decreased from the initial marsh soil value of 0.7 to values of 0.3 within only 50 years of paddy management. Rotation between paddy- and upland-type cultivation resulted in a comparatively high $\mathrm{TEX}_{86}$ value of 0.5 in the 2000year-old paddy soils (Fig. 10b). Our results thus suggest that management systems significantly affect the microbial soil community. Long-time paddy management also led to the successive increase in ammonia-oxidizing Thaumarchaeota based on high relative abundances of crenarchaeol, indicating either a recovery process of water-stressed soil Thaumarchaeota or the enrichment of fossil crenarchaeol. The latter is potentially explained by the management type used in the Cixi area, with one wetland rice season and one dry intercrop season per year that influence the presence of aerobic and anaerobic microbes in these paddy soils. In particular, the periodically anaerobic conditions may result in a slower degradation of organic matter (Lal et al., 2002). GDGTs may originate from a mixed source of microbial membrane lipids that were recently deposited (during the oxic as well as in the anoxic period) additionally to the previously preserved ones. 
Thus, higher proportions of crenarchaeol, e.g., as marker for terrestrial ammonia oxidizers, being active during the oxic intercrop period, were detected but in lower amounts than commonly observed in upland soils (Table S1). At the same time, the proportion of methanogenic archaea, which was estimated by using the GDGT- 0 / crenarchaeol ratio, decreased during the long-term paddy management from 5.0 in the 50 year-old to 2.8 in the 2000 -year-old paddy soil.

The $\mathrm{pH}$ values ranged between 8.0 in marsh soil and 5.5 in the 2000-year paddy soil. The paddy management (including flooding practices) thus leads to enhanced decalcification of soils compared to the non-flooded upland management. However, most soils have an alkaline or neutral $\mathrm{pH}$ with exception of the 700-year upland soil and the 2000-year paddy soils, which all had $\mathrm{pH}$ values < 6.5 (Fig. S5a). It has previously been demonstrated that the CBT is negatively correlated with increasing $\mathrm{pH}$ values (Weijers et al., 2007; Peterse et al., 2012). In the soils of the Cixi chronosequences a negative correlation was also observed, which was higher for paddy soils $\left(r=-0.94, r^{2}=0.88, n=4, p<0.001\right)$ than for upland soils $\left(r=-0.69, r^{2}=0.47, n=5, p<0.001\right)$. Interestingly, an offset of CBT values between paddy and upland soils with no apparent changes during cultivation time was noted (Fig. 10c). In addition, the CBT was higher in the younger of both marsh soils, probably because of the greater soil water content in the $\sim 10$-year-old compared to the $\sim 35$-year-old marsh soil as a result of the progressive dewatering during marsh soil pedogenesis. The observation regarding the CBT values supports the idea that soil moisture, in addition to $\mathrm{pH}$, controls the degree of cyclization of brGDGTs under alkaline conditions, possibly as a reaction to water stress or oxygen deprivation in microorganisms. The increase in CBT values in acidic soils (Fig. 10c) also suggests that low soil $\mathrm{pH}$ results in the increased synthesis of brGDGTs with no cyclopentyl moieties.

Except for the youngest paddy soils (50 years), the $\mathrm{MBT}^{\prime}$ was slightly lower in Cixi upland soils compared to their corresponding paddy soils with identical cultivation time (Fig. 10d). This is in contrast to the observations that paddy soils in general showed a lower MBT $^{\prime}$ compared to the adjacent upland soils (Fig. 6b). This may indicate that soil bacteria living under contrasting $\mathrm{pH}$ regimes adapt the composition of their membrane lipids in a different fashion, even if the agricultural management is comparable.

The CBT and $\mathrm{MBT}^{\prime}$ are both considered to be strongly related to MAT (Weijers et al., 2007; Peterse et al., 2012), which is largely similar for paddy and upland soils from the same sampling region. However, the calculated $T_{\mathrm{MC}}$ was different in adjacent paddy and upland soils (Table S1) and gradually increased during long-term management in both chronosequences (Fig. 11) from 14.4 to $17.8^{\circ} \mathrm{C}$ in paddy soils and from 17.1 to $19.3{ }^{\circ} \mathrm{C}$ in upland soils. In general, temperatures were approximately $1.4^{\circ} \mathrm{C}$ higher in upland soils compared to soils under paddy management with the same cultivation time. This implies that the management type affects the MST, which in turn controls the membrane lipid composition of brGDGT-producing bacteria.

\section{Conclusions}

Our results show that archaeal and bacterial GDGTs were ubiquitously distributed in paddy, upland, forest, bushland and marsh soils of tropical and subtropical climate regimes. Independent of soil usage, brGDGTs predominated over iGDGTs in all soils but had lower relative proportions in soils located in the subtropics compared to soils at tropical latitudes. This implies that warm and humid environments favour an increased occurrence of brGDGT in the GDGT pool. The distribution patterns of iGDGTs indicate no differences in archaeal/thaumarchaeal composition dependent on climatic exposition.

Agricultural management was a major factor that controlled the distribution of the archaeal community in soils. In subaquatic paddy soils, the lower proportion of crenarchaeol compared to other iGDGTs indicates an enhanced presence of methanogenic archaea compared to ammonia-oxidizing Thaumarchaeota, which were more abundant in dry upland soils. In addition, the intensity and duration of rice cultivation significantly affected the composition of iGDGT with an increase in the GDGT-0 / crenarchaeol ratio in soils with a higher number of rice cultivation cycles per year.

CBT values were correlated with soil $\mathrm{pH}$ and were controlled by a predominance of acyclic brGDGT in acidic soils. In alkaline soils, CBT values were rather invariant but the offset between soils under periodical flooding (paddy soils) and soils under non-flooded upland management suggests that parameters other than $\mathrm{pH}$ affected the distribution of brGDGTs as well (e.g. soil moisture, which in addition to soil $\mathrm{pH}$ and MAT exerts a control on the degree of cyclization of brGDGTs). MBT $^{\prime}$ values differed in adjacent paddy and upland soils, confirming that factors other than MAT and MAP affect the degree of methylation of brGDGT on a regional scale. brGDGT-based temperatures $\left(T_{\mathrm{MC}}\right)$ were higher in soils under upland management than under paddy management, and these differences in $T_{\mathrm{MC}}$ suggest that the specific management influenced the soil moisture, which in turn affects MST. The results of the Cixi chronosequence covering 2000 years of soil development confirm that the SOC, the $\mathrm{pH}$ value and the soil moisture controlled the distribution of brGDGT during long-term paddy soil usage. 


\section{Appendix A}

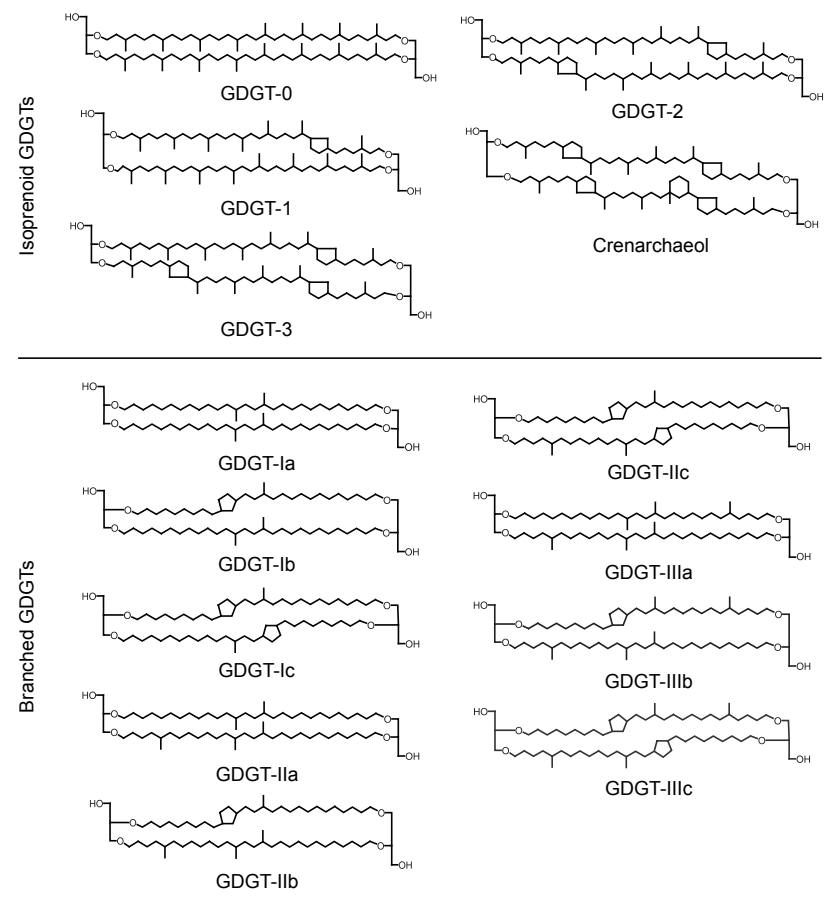

Figure A1. Chemical structures of branched GDGTs (brGDGTs) and isoprenoid GDGTs (iGDGTs) investigated in this study. 


\section{The Supplement related to this article is available online at doi:10.5194/bg-13-1647-2016-supplement.}

Acknowledgements. J. Tuo and the two anonymous reviewers are thanked for their comments, which have improved this paper. We thank the German Research Foundation (DFG) for financial support (Schw554/20). Asian and European partners of Research Initiative FOR 995 as well as of the LEGATO project are thanked for field work collaboration.

Edited by: Y. Kuzyakov

\section{References}

Aanderud, Z. T., Jones, S. E., Fierer, N., and Lennon, J. T.: Resuscitation of the rare biosphere contributes to pulses of ecosystem activity, Front. Microbiol., 6, 1-11, 2015.

Angel, R., Claus, P., and Conrad, R.: Methanogenic archaea are globally ubiquitous in aerated soils and become active under wet anoxic conditions, ISME J., 6, 847-862, 2012.

Awe, G. O., Reichert, J. M., and Wendroth, O. O.: Temporal variability and covariance structures of soil temperature in a sugarcane field under different management practices in southern Brazil, Soil Till. Res., 150, 93-106, 2015.

Ayari, A., Yang, H., and Xie, S.: Flooding impact on the distribution of microbial tetraether lipids in paddy rice soil in China, Front. Earth Sci., 7, 384-394, 2013.

Bannert, A., Mueller-Niggemann, C., Kleineidam, K., Wissing, L., Cao, Z. H., Schwark, L., and Schloter, M.: Comparison of lipid biomarker and gene abundance characterizing the archaeal ammonia-oxidizing community in flooded soils, Biol. Fert. Soils, 47, 839-843, 2011.

Bauersachs, T., Weidenbach, K., Schmitz, R. A., and Schwark, L.: Distribution of glycerol ether lipids in halophilic, methanogenic and hyperthermophilic archaea, Org. Geochem., 83-84, 101$108,2015$.

Bischoff, J., Mangelsdorf, K., Schwamborn, G., and Wagner, D.: Impact of lake-level and climate changes on microbial communities in a terrestrial permafrost sequence of the El'gygytgyn crater, Far East Russian Arctic, Permafrost Periglac., 25, 107116, 2014.

Blaga, C. I., Reichart, G. J., Heiri, O., and Sinninghe Damsté, J. S.: Tetraether membrane lipid distributions in water-column particulate matter and sediments: a study of 47 European lakes along a north-south transect, J. Paleolimnol., 41, 523-540, 2009.

Blumenberg, M., Seifert, R., Reitner, J., Pape, T., and Michaelis, W.: Membrane lipid patterns typify distinct anaerobic methanotrophic consortia, P. Natl. Acad. Sci. USA, 101, 11111-11116, 2004.

Boetius, A., Ravenschlag, K., Schubert, C. J., Rickert, D., Widdel, F., Gleseke, A., Amann, R., Jørgensen, B. B., Witte, U., and Pfannkuche, O.: A marine microbial consortium apparently mediating anaerobic oxidation methane, Nature, 407, 623-626, 2000.
Cheng, Y. Q., Yang, L. Z., Cao, Z. H., Ci, E., and Yin, S.: Chronosequential changes of selected pedogenic properties in paddy soils as compared with non-paddy soils, Geoderma, 151, 31-41, 2009.

Coffinet, S., Huguet, A., Williamson, D., Fosse, C., and Derenne, S.: Potential of GDGTs as a temperature proxy along an altitudinal transect at Mount Rungwe (Tanzania), Org. Geochem., 68, 8289, 2014.

Conrad, R.: Microbial ecology of methanogens and methanotrophs, Adv. Agron., 96, 1-63, 2007.

De Jonge, C., Hopmans, E. C., Stadnitskaia, A., Rijpstra, W. I. C., Hofland, R., Tegelaar, E., and Sinninghe Damsté, J. S.: Identification of novel penta- and hexamethylated branched glycerol dialkyl glycerol tetraethers in peat using HPLC-MS ${ }^{2}$, GC-MS and GC-SMB-MS, Org. Geochem., 54, 78-82, 2013.

De Jonge, C., Hopmans, E. C., Zell, C. I., Kim, J. H., Schouten, S., and Sinninghe Damsté, J. S.: Occurrence and abundance of 6-methyl branched glycerol dialkyl glycerol tetraethers in soils: Implications for palaeoclimate reconstruction, Geochim. Cosmochim. Ac., 141, 97-112, 2014.

Elling, F. J., Könneke, M., Mußmann, M., Greve, A., and Hinrichs, K.-U.: Influence of temperature, $\mathrm{pH}$, and salinity on membrane lipid composition and TEX86 of marine planktonic thaumarchaeal isolates, Geochim. Cosmochim. Ac., 171, 238-255, doi:10.1016/j.gca.2015.09.004, 2015.

Edit Committee of Chorography of Cixi County: Chorography of Cixi County, Zhejiang, Peoples Express House, Hangzhou, 1992.

FAO: World agriculture: towards 2015/2030, An FAO perspective, edited by: Bruinsma, J., Earthscan Publications Ltd, London, 2003.

Feng, L. H. and Bao, Y. X.: Impact of human activity on the estuary of the Qiantang River and the reclamation of tidal flats and river regulation, Environ. Geol., 49, 76-81, 2005.

Frostegård, Å., Bååth, E., and Tunlid, A.: Shifts in the structure of soil microbial communities in limed forests as revealed by phospholipid fatty acid analysis, Soil Biol. Biochem., 25, 723-730, 1993.

Heyng, A. M., Mayr, C., Lücke, A., Moschen, R., Wissel, H., Striewski, B., and Bauersachs, T.: Middle and Late Holocene paleotemperatures reconstructed from oxygen isotopes and GDGTs of sediments from Lake Pupuke, New Zealand, Quatern. Int., 374, 3-14, 2015.

Hopmans, E. C., Schouten, S., Pancost, R. D., van der Meer, M. T. J., and Sinninghe Damsté, J. S.: Analysis of intact tetraether lipids in archaeal cell material and sediments by high performance liquid chromatography/atmospheric pressure chemical ionization mass spectrometry, Rapid Commun. Mass Sp.., 14, 585-589, 2000.

Hopmans, E. C., Weijers, J. W. H., Schefuß, E., Herfort, L., Sinninghe Damsté, J. S., and Schouten S.: A novel proxy for terrestrial organic matter in sediments based on branched and isoprenoid tetraether lipids, Earth Planet. Sc. Lett., 224, 107-116, 2004.

Huguet, A., Fosse, C., Metzger, P., Fritsch, E., and Derenne, S.: Occurrence and distribution of extractable glycerol dialkyl glycerol tetraethers in podzols, Org. Geochem., 41, 291-301, 2010.

Huguet, A., Wiesenberg, G. L. B., Gocke, M., Fosse, C., and Derenne, S.: Branched tetraether membrane lipids associated with rhizoliths in loess: Rhizomicrobial overprinting of initial biomarker record, Org. Geochem., 43, 12-19, 2012. 
Huguet, A., Grossi, V., Belmahdi, I., Fosse, C., and Derenne, S.: Archaeal and bacterial tetraether lipids in tropical ponds with contrasted salinity (Guadeloupe, French West Indies): Implications for tetraether-based environmental proxies, Org. Geochem., 8384, 158-169, 2015.

Husson, O.: Redox potential (Eh) and $\mathrm{pH}$ as drivers of soil/plant/microorganism systems: a transdisciplinary overview pointing to integrative opportunities for agronomy, Plant Soil, 362, 389-417, 2013.

Jiang, X., Hou, X., Zhou, X., Xin, X., Wright, A., and Jia, Z.: pH regulates key players of nitrification in paddy soils, Soil Biol. Biochem., 81, 9-16, 2015.

Koga, Y. and Morii, H.: Recent advances in structural research on ether lipids from archaea including comparative and physiological aspects, Biosci. Biotech. Bioch., 69, 2019-2034, 2005.

Koga, Y., Morii, H., Akagawa-Matsushita, M., and Ohga, M.: Correlation of polar lipid composition with $16 \mathrm{~S}$ rRNA phylogeny in methanogens. Further analysis of lipid component parts, Biosci. Biotech. Bioch., 62, 230-236, 1998.

Kögel-Knabner, I., Amelung, W., Cao, Z. H., Fiedler, S., Frenzel, P., Jahn, R., Kalbitz, K., Kölbl, A., and Schloter, M.: Biogeochemistry of paddy soils, Geoderma, 157, 1-14, 2010.

Kölbl, A., Schad, P., Jahn, R., Amelung, W., Bannert, A., Cao, Z. H., Fiedler, S., Kalbitz, K., Lehndorff, E., Müller-Niggemann, C., Schloter, M., Schwark, L., Vogelsang, V., Wissing, L., and Kögel-Knabner, I.: Accelerated soil formation due to paddy management on marshlands (Zhejiang Province, China), Geoderma, 228-229, 67-89, 2014.

Klotzbücher, T., Marxen, A., Vetterlein, D., Schneiker, J., Türke, M., van Sinh, N., Manh, N. H., van Chien, H., Marquez, L., Villareal, S., Bustamante, J. V., and Jahn, R.: Plantavailable silicon in paddy soils as a key factor for sustainable rice production in Southeast Asia, Basic Appl. Ecol., doi:10.1016/j.baae.2014.08.002, in press, 2014.

Krüger, M., Meyerdierks, A., Glöckner, F. O., Amann, R., Widdel, F., Kube, M., Reinhardt, R., Kahnt, J., Böcher, R., Thauer, R. K., and Shima, S.: A conspicuous nickel protein in microbial mats that oxidize methane anaerobically, Nature, 426, 878-881, 2003.

Krüger, M., Frenzel, P., Kemnitz, D., and Conrad, R., Activity, structure and dynamics of the methanogenic archaeal community in a flooded Italian rice field, FEMS Microbiol. Ecol., 51, 323-331, 2005.

Lal, R.: Soil carbon sequestration in China through agricultural intensification, and restoration of degraded and desertified ecosystems, Land Degrad. Dev., 13, 469-478, 2002.

Leininger, S., Urich, T., Schloter, M., Schwark, L., Qi, J., Nicol, G. W., Prosser, J. I., Schuster, S. C., and Schleper, C.: Archaea predominate among ammonia-oxidizing prokaryotes in soils, Nature, 442, 806-809, 2006.

Liesack, W., Schnell, S., and Revsbech, N. P.: Microbiology of flooded rice paddies, FEMS Microbiol. Rev., 24, 625-645, 2000.

Liu, W., Wang, H., Zhang, C. L., Liu, Z., and He, Y.: Distribution of glycerol dialkyl glycerol tetraether lipids along an altitudinal transect on Mt. Xiangpi, NE Qinghai-Tibetan Plateau, China, Org. Geochem., 57, 76-83, 2013.

Liu, Y., Wang, J., Liu, D., Li, Z., Zhang, G., Tao, Y., Xie, J., Pan, J., and Chen, F.: Straw mulching reduces the harmful effects of extreme hydrological and temperature conditions in citrus orchards, PLoS One, 9, e87094, doi:10.1371/journal.pone.0087094, 2014.
Loomis, S. E., Russell, J. M., Heureux, A. M., D’Andrea, W. J., and Sinninghe Damsté, J. S.: Seasonal variability of branched glycerol dialkyl glycerol tetraethers (brGDGTs) in a temperate lake system, Geochim. Cosmochim. Ac., 144, 173-187, 2014.

Mueller-Niggemann, C. and Schwark, L.: Chemotaxonomy and diagenesis of aliphatic hydrocarbons in rice plants and soils from land reclamation areas in the Zhejiang Province, China, Org. Geochem., 83-84, 215-226, 2015.

Mueller-Niggemann, C., Bannert, A., Schloter, M., Lehndorff, E., and Schwark, L.: Intra- versus inter-site macroscale variation in biogeochemical properties along a paddy soil chronosequence, Biogeosciences, 9, 1237-1251, doi:10.5194/bg-9-12372012, 2012.

Naeher, S., Peterse, F., Smittenberg, R. H., Niemann, H., Zigah, P. K., and Schubert, C. J.: Sources of glycerol dialkyl glycerol tetraethers (GDGTs) in catchment soils, water column and sediments of Lake Rotsee (Switzerland) - Implications for the application of GDGT-based proxies for lakes, Org. Geochem., 66, 164-173, 2014.

Offre, P., Spang, A., and Schleper, C.: Archaea in Biogeochemical Cycles, Annu. Rev. Microbiol., 67, 437-457, 2013.

Oppermann, B. I., Michaelis, W., Blumenberg, M., Frerichs, J., Schulz, H. M., Schippers, A., Beaubien, S. E., and Krüger, M.: Soil microbial community changes as a result of long-term exposure to a natural $\mathrm{CO}_{2}$ vent, Geochim. Cosmochim. Ac., 74, 2697-2716, 2010.

Oton, E. V., Quince, C., Nicol, G. W., Prosser, J. I., and GubryRangin, C.: Phylogenetic congruence and ecological coherence in terrestrial Thaumarchaeota, ISME J., 10, 85-96, 2016.

Pancost, R. D., Hopmans, E. C., and Sinninghe Damsté, J. S.: Archaeal lipids in mediterranean cold seeps: Molecular proxies for anaerobic methane oxidation, Geochim. Cosmochim. Ac., 65, 1611-1627, 2001.

Pearson, A. and Ingalls, A. E.: Assessing the Use of Archaeal Lipids as Marine Environmental Proxies, Annu. Rev. Earth Pl. Sc., 41, 359-384, 2013.

Pearson, A., Huang, Z., Ingalls, A. E., Romanek, C. S., Wiegel, J., Freeman, K. H., Smittenberg, R. H., and Zhang, C. L.: Nonmarine crenarchaeol in Nevada hot springs, Appl. Environ. Microb., 70, 5229-5237, 2004.

Pester, M., Rattei, T., Flechl, S., Gröngröft, A., Richter, A., Overmann, J., Reinhold-Hurek, B., Loy, A., and Wagner, M.: AmoAbased consensus phylogeny of ammonia-oxidizing archaea and deep sequencing of amoA genes from soils of four different geographic regions, Environ. Microbiol., 14, 525-539, 2012.

Peterse, F., Schouten, S., van der Meer, J., van der Meer, M. T. J., and Sinninghe Damsté, J. S.: Distribution of branched tetraether lipids in geothermally heated soils: Implications for the MBT/CBT temperature proxy, Org. Geochem., 40, 201-205, 2009a.

Peterse, F., Kim, J. H., Schouten, S., Kristensen, D. K., Koç, N., and Sinninghe Damsté, J. S.: Constraints on the application of the MBT/CBT palaeothermometer at high latitude environments (Svalbard, Norway), Org. Geochem., 40, 692-699, 2009b.

Peterse, F., van der Meer, M. T. J., Schouten, S., Jia, G., Ossebaar, J., Blokker, J., and Sinninghe Damsté, J. S.: Assessment of soil $n$-alkane $\delta \mathrm{D}$ and branched tetraether membrane lipid distributions as tools for paleoelevation reconstruction, Biogeosciences, 6, 2799-2807, doi:10.5194/bg-6-2799-2009, 2009c. 
Peterse, F., van der Meer, J., Schouten, S., Weijers, J. W. H., Fierer, N., Jackson, R. B., Kim, J. H., and Sinninghe Damsté, J. S.: Revised calibration of the MBT-CBT paleotemperature proxy based on branched tetraether membrane lipids in surface soils, Geochim. Cosmochim. Ac., 96, 215-229, 2012.

Peterse, F., Moy, C. M., and Eglinton, T. I.: A laboratory experiment on the behaviour of soil-derived core and intact polar GDGTs in aquatic environments, Biogeosciences, 12, 933-943, doi:10.5194/bg-12-933-2015, 2015.

Pitcher, A., Schouten, S., and Sinninghe Damsté, J. S.: In situ production of crenarchaeol in two California hot springs, Appl. Environ. Microb., 75, 4443-4451, 2009.

Pitcher, A., Rychlik, N., Hopmans, E. C., Spieck, E., Rijpstra, W. I. C., Ossebaar, J., Schouten, S., Wagner, M., and Sinninghe Damsté, J. S.: Crenarchaeol dominates the membrane lipids of Candidatus Nitrososphaera gargensis, a thermophilic group I.1b Archaeon, ISME J., 4, 542-552, 2010.

Pitcher, A., Hopmans, E. C., Mosier, A. C., Park, S. J., Rhee, S. K., Francis, C. A., Schouten, S., and Sinninghe Damsté, J. S.: Core and intact polar glycerol dibiphytanyl glycerol tetraether lipids of ammonia-oxidizing Archaea enriched from marine and estuarine sediments, Appl. Environ. Microb., 77, 3468-3477, 2011.

Reigstad, L. J., Richter, A., Daims, H., Urich, T., Schwark, L., and Schleper, C.: Nitrification in terrestrial hot springs of Iceland and Kamchatka, FEMS Microbiol. Ecol., 64, 167-174, 2008.

Sahrawat, K. L.: Fertility and organic matter in submerged rice soils, Curr. Sci., 88, 735-739, 2005.

Schouten, S., Hopmans, E. C., Schefuß, E., and Sinninghe Damsté, J. S.: Distributional variations in marine crenarchaeotal membrane lipids: A new tool for reconstructing ancient sea water temperatures?, Earth Planet. Sc. Lett., 204, 265-274, 2002.

Schouten, S., Huguet, C., Hopmans, E. C., Kienhuis, M. V. M., and Sinninghe Damsté, J. S.: Analytical methodology for TEX 86 paleothermometry by high-performance liquid chromatography/atmospheric pressure chemical ionization-mass spectrometry, Anal. Chem., 79, 2940-2944, 2007.

Schouten, S., Rijpstra, W. I. C., Durisch-Kaiser, E., Schubert, C. J., and Sinninghe Damsté, J. S.: Distribution of glycerol dialkyl glycerol tetraether lipids in the water column of Lake Tanganyika, Org. Geochem., 53, 34-37, 2012.

Schouten, S., Hopmans, E. C., and Sinninghe Damsté, J. S.: The organic geochemistry of glycerol dialkyl glycerol tetraether lipids: A review, Org. Geochem., 54, 19-61, 2013.

Seneviratne, S. I., Corti, T., Davin, E. L., Hirschi, M., Jaeger, E. B., Lehner, I., Orlowsky, B., and Teuling, A. J.: Investigating soil moisture-climate interactions in a changing climate: A review, Earth-Sci. Rev., 99, 125-161, 2010.

Serrano-Silva, N., Sarria-Guzmán, Y., Dendooven, L., and LunaGuido, M.: Methanogenesis and methanotrophy in soil: A review, Pedosphere, 24, 291-307, 2014.

Shima, S., Krueger, M., Weinert, T., Demmer, U., Kahnt, J., Thauer, R. K., and Ermler, U.: Structure of a methyl-coenzyme M reductase from Black Sea mats that oxidize methane anaerobically, Nature, 481, 98-101, 2012.

Sinninghe Damsté, J. S., Hopmans, E. C., Pancost, R. D., Schouten, S., and Geenevasen, J. A. J.: Newly discovered non-isoprenoid glycerol dialkyl glycerol tetraether lipids in sediments, Chem. Commun., 17, 1683-1684, 2000.
Sinninghe Damsté, J. S., Schouten, S., Hopmans, E. C., van Duien, A. C. T., and Geenevasen, J. A. J.: Crenarchaeol: the characteristic core glycerol dibiphytanyl glycerol tetraether membrane lipid of cosmopolitan pelagic crenarchaeota, J. Lipid Res., 43, 16411651, 2002.

Sinninghe Damsté, J. S., Ossebaar, J., Schouten, S., and Verschuren, D.: Altitudinal shifts in the branched tetraether lipid distribution in soil from Mt. Kilimanjaro (Tanzania): Implications for the MBT/CBT continental palaeothermometer, Org. Geochem., 39, 1072-1076, 2008.

Sinninghe Damsté, J. S., Rijpstra, W. I. C., Hopmans, E. C., Weijers, J. W. H., Foesel, B. U., Overmann, J., and Dedysh, S. N.: 13,16Dimethyl octacosanedioic acid (iso-Diabolic Acid), a common membrane-spanning lipid of Acidobacteria subdivisions 1 and 3, Appl. Environ. Microb., 77, 4147-4154, 2011.

Sinninghe Damsté, J. S., Rijpstra, W. I. C., Hopmans, E. C., Jung, M. Y., Kim, J. G., Rhee, S. K., Stieglmeier, M., and Schleper, C.: Intact polar and core glycerol dibiphytanyl glycerol tetraether lipids of group I.1a and I.1b Thaumarchaeota in soil, Appl. Environ. Microb., 78, 6866-6874, 2012.

Sinninghe Damsté, J. S., Rijpstra, W. I. C., Hopmans, E. C., Foesel, B. U., Wüst, P. K., Overmann, J., Tank, M., Bryant, D. A., Dunfield, P. F., Houghton, K., and Stott, M. B.: Ether- and ester-bound iso-diabolic acid and other lipids in members of Acidobacteria subdivision 4, Appl. Environ. Microb., 80, 52075218, 2014.

Stahl, D. A. and de la Torre, J. R.: Physiology and diversity of ammonia-oxidizing archaea, Annu. Rev. Microbiol., 66, 83-101, 2012.

Thauer, R. K., Kaster, A.-K., Seedorf, H., Buckel, W., and Hedderich, R.: Methanogenic archaea: ecologically relevant differences in energy conservation, Nat. Rev. Microbiol., 6, 579-591, 2008.

Tierney, J. E. and Russell, J. M.: Distributions of branched GDGTs in a tropical lake system: Implications for lacustrine application of the MBT/CBT paleoproxy, Org. Geochem., 40, 1032-1036, 2009.

Tierney, J. E., Schouten, S., Pitcher, A., Hopmans, E. C., and Sinninghe Damsté, J. S.: Core and intact polar glycerol dialkyl glycerol tetraethers (GDGTs) in Sand Pond, Warwick, Rhode Island (USA): Insights into the origin of lacustrine GDGTs, Geochim. Cosmochim. Ac., 77, 561-581, 2012.

Villanueva, L., Damsté, J. S. S., and Schouten, S.: A re-evaluation of the archaeal membrane lipid biosynthetic pathway, Nat. Rev. Microbiol., 12, 438-448, 2014.

Wang, H., Liu, W., Zhang, C. L., Liu, Z., and He, Y.: Branched and isoprenoid tetraether (BIT) index traces water content along two marsh-soil transects surrounding Lake Qinghai: Implications for paleo-humidity variation, Org. Geochem., 59, 75-81, 2013.

Wang, H., Liu, W., and Zhang, C. L.: Dependence of the cyclization of branched tetraethers on soil moisture in alkaline soils from arid-subhumid China: implications for palaeorainfall reconstructions on the Chinese Loess Plateau, Biogeosciences, 11, 67556768, doi:10.5194/bg-11-6755-2014, 2014.

Watanabe, T., Kimura, M., and Asakawa, S.: Community structure of methanogenic archaea in paddy field soil under double cropping (rice-wheat), Soil Biol. Biochem., 38, 1264-1274, 2006.

Watanabe, T., Kimura, M., and Asakawa, S.: Distinct members of a stable methanogenic archaeal community transcribe mcrA genes 
under flooded and drained conditions in Japanese paddy field soil, Soil Biol. Biochem., 41, 276-285, 2009.

Watanabe, T., Hosen, Y., Agbisit, R., Llorca, L., Katayanagi, N., Asakawa, S., and Kimura, M.: Changes in community structure of methanogenic archaea brought about by water-saving practice in paddy field soil, Soil Biol. Biochem., 58, 235-243, 2013.

Weijers, J. W. H., Schouten, S., Hopmans, E. C., Geenevasen, J. A. J., David, O. R. P., Coleman, J. M., Pancost, R. D., and Sinninghe Damsté, J. S.: Membrane lipids of mesophilic anaerobic bacteria thriving in peats have typical archaeal traits, Environ. Microbiol., 8, 648-657, 2006a.

Weijers, J. W. H., Schouten, S., Spaargaren, O. C., and Sinninghe Damsté, J. S.: Occurrence and distribution of tetraether membrane lipids in soils: Implications for the use of the $\mathrm{TEX}_{86}$ proxy and the BIT index, Org. Geochem., 37, 1680-1693, $2006 \mathrm{~b}$.

Weijers, J. W. H., Schouten, S., van den Donker, J. C., Hopmans, E. C., and Sinninghe Damsté, J. S.: Environmental controls on bacterial tetraether membrane lipid distribution in soils, Geochim. Cosmochim. Ac., 71, 703-713, 2007.

Weijers, J. W. H., Panoto, E., van Bleijswijk, J., Schouten, S., Rijpstra, W. I. C., Balk, M., Stams, A. J. M., and Sinninghe Damsté, J. S.: Constraints on the biological source(s) of the orphan branched tetraether membrane lipids, Geomicrobiol. J., 26, 402-414, 2009.

Weijers, J. W. H., Wiesenberg, G. L. B., Bol, R., Hopmans, E. C., and Pancost, R. D.: Carbon isotopic composition of branched tetraether membrane lipids in soils suggest a rapid turnover and a heterotrophic life style of their source organism(s), Biogeosciences, 7, 2959-2973, doi:10.5194/bg-7-2959-2010, 2010.
Wu, J.: Carbon accumulation in paddy ecosystems in subtropical China: Evidence from landscape studies, Eur. J. Soil Sci., 62, 29-34, 2011.

Wuchter, C., Schouten, S., Coolen, M. J. L., and Sinninghe Damsté, J. S.: Temperature-dependent variation in the distribution of tetraether membrane lipids of marine Crenarchaeota: Implications for TEX 86 paleothermometry, Paleoceanography, 19, PA4028, doi:10.1029/2004PA001041, 2004.

Xie, W., Zhang, C., and Ma, C.: Temporal variation in community structure and lipid composition of Thaumarchaeota from subtropical soil: Insight into proposing a new soil pH proxy, Org. Geochem., 83-84, 54-64, doi:10.1016/j.orggeochem.2015.02.009, 2015.

Xiong, Z. Q., Xing, G. X., and Zhu, Z. L.: Nitrous oxide and methane emissions as affected by water, soil and nitrogen, Pedosphere, 17, 146-155, 2007.

Yang, H., Pancost, R. D., Jia, C., and Xie, S.: The Response of Archaeal Tetraether Membrane Lipids in Surface Soils to Temperature: A Potential Paleothermometer in Paleosols, Geomicrobiol. J., 33, 98-109, 2016.

Zink, K.-G., Vandergoes, M. J., Mangelsdorf, K., DieffenbacherKrall, A. C., and Schwark, L.: Application of bacterial glycerol dialkyl glycerol tetraethers (GDGTs) to develop modern and past temperature estimates from New Zealand lakes, Org. Geochem., 41, 1060-1066, 2010. 